\title{
Breast Cancer Chemo-immunotherapy through Liposomal Delivery of an Immunogenic Cell Death Stimulus Plus Interference in the IDO-1 Pathway
}

Jianqin Lu, ${ }^{\dagger, \ddagger \odot ~ X i a n g s h e n g ~ L i u, ~}{ }^{\dagger}{ }^{\dagger \odot}$ Yu-Pei Liao, ${ }^{\dagger}$ Xiang Wang, ${ }^{\ddagger}$ Ayman Ahmed, ${ }^{\dagger}$ Wen Jiang, ${ }^{\dagger}$ Ying Ji, ${ }^{\dagger}$

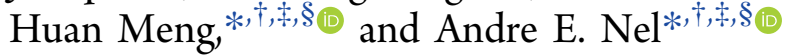

Division of NanoMedicine, Department of Medicine, David Geffen School of Medicine, ${ }^{\ddagger}$ Center for Environmental Implications of Nanotechnology, California NanoSystems Institute, and ${ }^{\S}$ Jonsson Comprehensive Cancer Center, University of California, Los Angeles, Los Angeles, California 90095, United States

\section{Supporting Information}

ABSTRACT: Immunotherapy provides the best approach to reduce the high mortality of metastatic breast cancer (BC). We demonstrate a chemo-immunotherapy approach, which utilizes a liposomal carrier to simultaneously trigger immunogenic cell death (ICD) as well as interfere in the regionally overexpressed immunosuppressive effect of indoleamine 2,3-dioxygenase (IDO-1) at the BC tumor site. The liposome was constructed by self-assembly of a phospholipid-conjugated prodrug, indoximod (IND), which inhibits the IDO-1 pathway, followed by the remote loading of the ICD-inducing chemo drug, doxorubicin (DOX). Intravenous injection of the encapsulated two-drug combination dramatically improved the pharmacokinetics and tumor drug concentrations of DOX and IND in an orthotopic 4T1 tumor model in syngeneic mice. Delivery of a threshold ICD stimulus resulted in the uptake of dying BC cells by dendritic cells, tumor antigen presentation and the activation/recruitment of naïve T-cells. The subsequent activation of perforin- and IFN- $\gamma$ releasing cytotoxic T-cells induced robust tumor cell killing at the primary as well as metastatic tumor sites. Immune phenotyping of the tumor tissues confirmed the recruitment of $\mathrm{CD8}^{+}$cytotoxic $\mathrm{T}$ lymphocytes (CTLs), disappearance of Tregs, and an increase in $\mathrm{CD8}^{+} / \mathrm{FOXP3}^{+} \mathrm{T}$-cell ratios. Not only does the $\mathrm{DOX} / \mathrm{IND}$-Liposome provide a synergistic antitumor response that is superior to a DOX-only liposome, but it also demonstrated that the carrier could be effectively combined with PD-1 blocking antibodies to eradicate lung metastases. All considered, an innovative nano-enabled approach has been established to allow deliberate use of ICD to switch an immune deplete to an immune replete BC microenvironment, allowing further boosting of the response by coadministered IDO inhibitors or immune checkpoint blocking antibodies.

KEYWORDS: immunogenic cell death, indoleamine 2,3-dioxygenase, immune checkpoint, chemo-immunotherapy, dual-delivery liposome, doxorubicin, breast cancer

\section{A} though the treatment of localized breast cancer $(\mathrm{BC})$ is highly successful with a 5 year survival rate of $\sim 90 \%$, metastatic breast cancer (MBC) is generally considered incurable with a high mortality rate, regardless of the use of radiation, chemotherapy, or estrogen blockers. ${ }^{1,2}$ In spite of the bleak picture for $\mathrm{MBC}$, optimism has emerged with the advent of cancer immunotherapy, which utilizes the power of $\mathrm{T}$-cell immunity to treat solid cancers, including BC. This is best exemplified by the use of immune checkpoint blocking antibodies, which have changed the treatment landscape for cancer, such as melanoma, renal cell carcinoma, and non-small cell lung cancer (NSCLC). ${ }^{3-5}$ However, BC is relatively resistant to treatment with checkpoint inhibitors, ${ }^{6}$ putatively because of its comparative immune deplete ("cold") microenvironment, absence of tumor-infiltrating lymphocytes (TILs), and expression of poorly potent cytotoxic $\mathrm{T}$ lymphocytes (CTLs) for the initiation of tumor killing., These data are also in agreement with the observation that $\mathrm{BC}$ tumors tend to express a low burden of nonsynonymous DNA mutations, which serve as the tumor antigen neo-epitopes capable of inducing a robust $\mathrm{T}$-cell response. ${ }^{8,9}$ This is also compatible with the notion that cancers with a high burden of

Received: July 9, 2018

Accepted: September 27, 2018

Published: October 16, 2018 


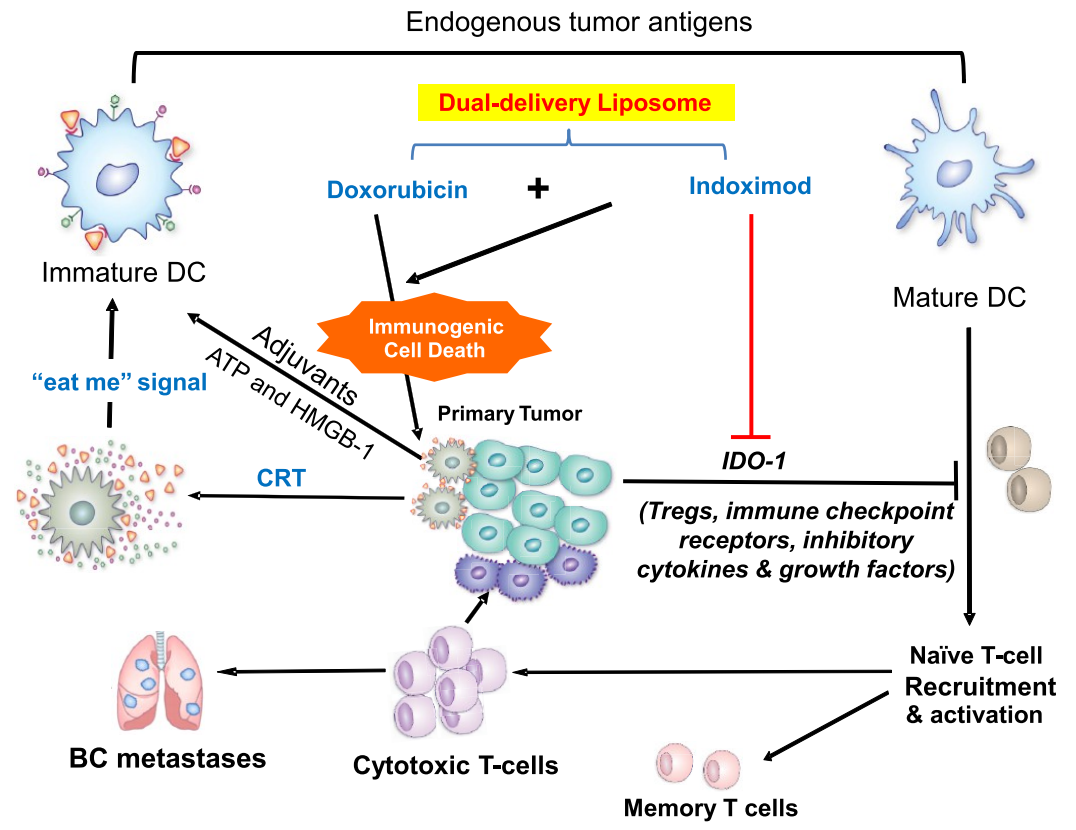

Figure 1. Schematic to explain BC immunotherapy by combined delivery of an immunogenic cell death stimulus plus an inhibitor of the IDO-1 pathway. Doxorubicin (DOX) delivery to the tumor site provides an effective stimulus for immunogenic cell death (ICD), which is characterized by calreticulin (CRT) expression (an "eat-me" signal for dendritic cell uptake) on the cancer cell surface. Subsequent release of adjuvant stimuli, HMGB-1 and ATP, by the dying cancer cells induce DC maturation and tumor antigen presentation to naïve T-cells. Recruitment of $\mathrm{CD8}^{+}$cytotoxic T-lymphocytes (CTLs) triggers a full-fledged immune response, provided that the tumor infiltrating lymphocytes (TILs) can escape the immunosuppressive micromilieu at the BC tumor site. These immunosuppressive pathways include a contribution by FOXP $-3^{+}$regulatory $\mathrm{T}$ cells, autoregulatory effects of immune checkpoint receptors (e.g., PD-1) and the metabolic effects of the overexpressed IDO-1 immune surveillance pathway. The small molecule inhibitor, indoximod (IND), interferes in the IDO-1 pathway. We propose that simultaneous delivery of DOX and IND through the use of a nanocarrier can effectively combine the use of an ICD stimulus and interference in an immune surveillance pathway for the development of $\mathrm{BC}$ immunotherapy. The improved pharmacokinetics of drug delivery by the nanocarrier allows achievement of sufficiently high tumor drug levels to trigger an effective and sustained immune response for the reduction or elimination of the primary $\mathrm{BC}$ tumor and its metastases.

nonsynonymous mutations are the most responsive to immune checkpoint inhibitors. ${ }^{10,11}$ In addition to its "cold" immune status, the strong immune suppressive micromilieu in the BC tumor site prevents effective T-cell priming. ${ }^{12,13}$ This includes a contribution from a number of immune suppressive mechanisms that are even more broadly oppressive than the checkpoint receptors being targeted by checkpoint blocking antibodies. $^{6,7}$

In addition to the utility of immune checkpoint inhibitors to initiate immunotherapy, chemotherapy can positively impact the immune system, leading to increased density of TILs at the BC tumor site, which correlates with improved disease prognosis. ${ }^{14-16}$ In this regard, Denkert et al. demonstrated in a large BC study that the density of TILs predicts pathological complete responses (pCRs) to neoadjuvant chemotherapy, including during treatment with docetaxel, DOX, and cyclophosphamide. $^{14}$ This is particularly evident in epidermal growth factor receptor 2-positive and triple negative (TNBC) disease. ${ }^{15}$ Moreover, neoadjuvant therapy with anthracycline drugs has demonstrated that an increase in the ratio of tumor-infiltrating $\mathrm{CD}^{+}$CTLs versus $\mathrm{FOXP3}^{+}$ regulatory $\mathrm{T}$-cells correlates with the elimination of hyperploid $\mathrm{BC}$ cells in post-treatment biopsy specimens. ${ }^{17,18}$ Because the presence of activated CTLs is accompanied by IFN- $\gamma$ production, which controls PD-L1 at the site of immune responsive cancers, ${ }^{19}$ it is noteworthy that PD-1 or PD-L1 receptor blocking antibodies could elicit significant objective response rates $(\sim 20 \%)$ in TNBC or HER2 ${ }^{-} / \mathrm{ER}^{+}$breast cancer tumors expressing $>1 \%$ PD-L1 on the tumor cell surface. ${ }^{20}$
In light of above observations, it is rational to ask whether the deliberate application of chemotherapeutic agents can reproducibly prime the immune response at the $\mathrm{BC}$ tumor site as a prelude to a practical approach for boosting immunotherapy to the immune checkpoint inhibitors. One possible approach is the use of chemo agents to induce immunogenic cell death (ICD) at the tumor site. ICD is a specialized form of tumor cell death that can be triggered by specific chemotherapeutic agents such as anthracyclines, taxanes, and oxaliplatin. ${ }^{21-23}$ ICD facilitates tumor antigen cross-presentation in dendritic cells as a result of calreticulin (CRT) expression on the dying tumor cell surface (Figure 1). ${ }^{21}$ CRT provides an "eat-me" signal for dendritic cell uptake via the CD91 receptor. ${ }^{24-27}$ Moreover, the delayed release of adjuvant stimuli, such as high mobility group box 1 protein (HMGB1; a TLR-4 ligand) and ATP (a danger signal that activates the NRLP3 inflammasome), provides additional stimuli for dendritic cell maturation and the ability to present tumor antigens to naïve T-cells. ${ }^{21,22,28-31}$ ICD provides a deliberate means of triggering TIL recruitment prior to response boosting by additional immune modulators, including antibodies that bind immune checkpoint receptors or metabolic immune surveillance pathways that prevent effective T-cell priming. ${ }^{32}$ An important example is the indoleamine 2,3dioxygenase (IDO-1) pathway that is overexpressed at the BC tumor site. ${ }^{33}$

How can ICD be used to invoke an orchestrated anti-BC immune response? Doxorubicin (DOX), an anthracycline agent, is a potent ICD inducer in addition to serving as a first- 

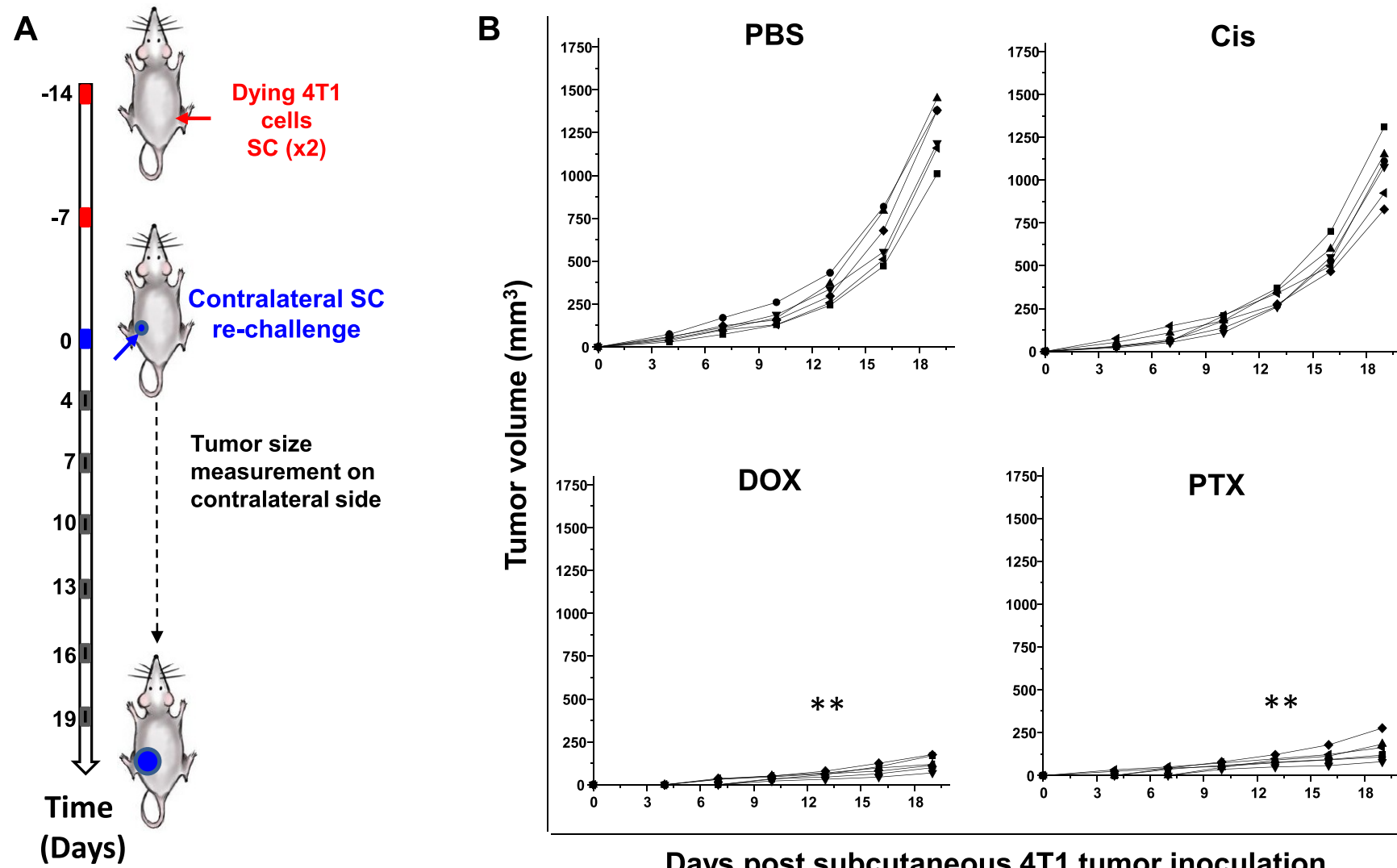

Days post subcutaneous 4T1 tumor inoculation

Figure 2. Use of a vaccination approach to identify chemo agents that induce ICD in a BC model. Published consensus guidelines were used to identify effective ICD introducing chemotherapy agents by a combination of in vitro 4T1 screening, followed by use of the dying tumor cells for a tumor vaccination procedure in syngeneic Balb/c mice. ${ }^{45}$ Multiparameter in vitro screening showed that doxorubicin (DOX) and paclitaxel (PTX), but not cisplatin (CIS), induced surface expression of CRT on 4T1 cells in a dose-dependent fashion, as well as quantifiable HMGB1 and ATP release (Figure S1B-D). (A) Animal vaccination, using 2 rounds of subcutaneous (SC) injection of dying 4T1 cells 7 days apart, followed by SC injection of live cells on the contralateral side. Successful growth inhibition at the challenge site is suggestive of immune interference. (B) Spaghetti plots showing growth inhibition of the tumors in animals vaccinated by dying tumor cells treated with DOX and PTX, but not CIS or PBS $(n=6)$. Evidence for the involvement of the innate and cognitive immune systems in the vaccination experiment appears in Figure $\mathrm{S} 1 \mathrm{~F}-\mathrm{H}$.

line chemotherapeutic drug for BC. ${ }^{26,34}$ It should be considered, however, that intravenous (IV) DOX administration is accompanied by off-target toxicity (e.g., of the heart and liver) and that the free drug has a relatively short circulatory half-life $\left(t_{1 / 2}\right)$, which limits tumor drug uptake. ${ }^{35-37}$ This could explain the poor potency or failure of free DOX to induce ICD at the $\mathrm{BC}$ tumor site in our preliminary animal studies (see later). To improve the pharmacokinetics (PK) for clinical use, encapsulated DOX delivery (e.g., the PEGylated liposomal DOX formulation, Doxil) has been successfully employed for the treatment of AIDS-related Kaposi's sarcoma, recurrent ovarial carcinoma, $\mathrm{MBC}$, and multiple myeloma. ${ }^{38-40}$ Moreover, our own preliminary data indicate that DOX encapsulation by an in-house liposome can effectively induce an ICD response at the tumor site in an orthotopic animal model (see later). We have also demonstrated in an orthotopic pancreas cancer (PC) model that it is possible to provide an effective ICD stimulus by using a mesoporous silica nanoparticle (MSNP) for delivery of oxaliplatin, which as a free drug was incapable of triggering an immunogenic response in vivo. ${ }^{22}$ All considered, these findings suggest that the use of a nanocarrier to improve the $\mathrm{PK}$ and tumor drug concentration of ICD-inducing chemotherapeutic agents could provide an effective means for initiating chemo-immunotherapy, which will be difficult to achieve on a reproducible basis by free drugs. Another potential advantage of using a nanocarrier is the ability to co-deliver synergistic drug combinations for improving treatment efficacy, as demonstrated in the PC tumor model, where contemporaneous delivery of 1-methyl-Dtryptophan (aka indoximod, IND) and oxaliplatin by the MSNP carrier triggered a synergistic immunotherapy response. $^{22}$ Not only did the indoximod strongly synergize with oxaliplatin in calreticulin expression, but it also provided effective interference in the IDO-1 immune suppressive pathway, which is regionally overexpressed at the PC tumor site. $^{22}$ The immunosuppressive effects of IDO- 1 is due to its enzymatic conversion of tryptophan to kynurenine, resulting in tryptophan insufficiency, which interferes in the mTOR pathway or activation of the serine/threonine-protein kinase, GCN2 (general control nonderepressible), or kynurenine in excess, which activates the aryl hydrocarbon receptor (AhR) pathway. ${ }^{41,42}$ A possible basis for the synergy between ICD induction and interference in the IDO-1 pathway could be there closely linked paracrine relationship in the tumor microenvironment. Collectively, these effects interfere in activation of cytotoxic $\mathrm{T}$ cells, accumulation of Tregs and an overall immune suppressive outcome at the site of the regional tumor and draining lymph nodes. There is currently a strong 
A
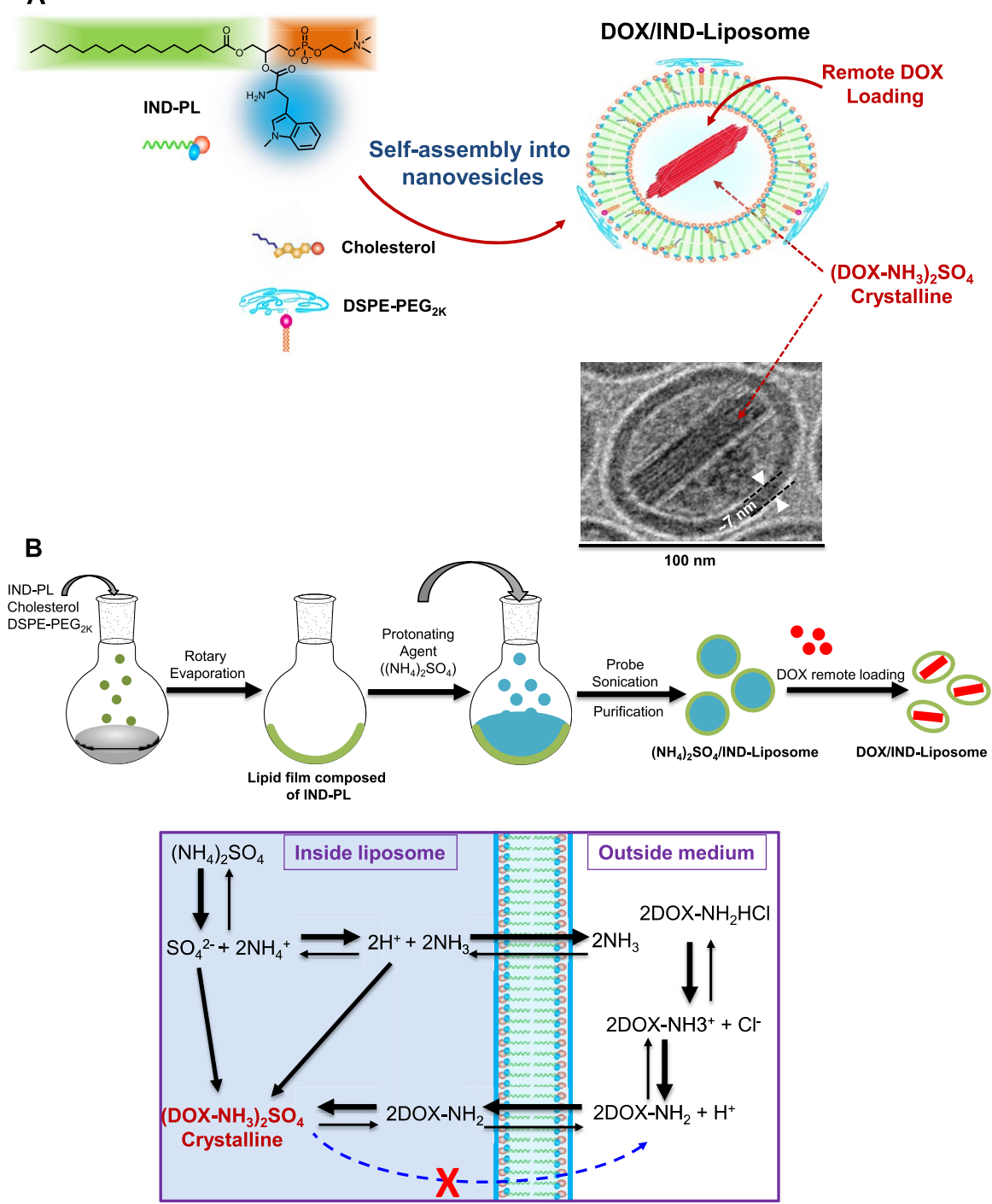

C

\begin{tabular}{c|c|c}
\hline & DOX/IND-Liposome & Dox-NP \\
\hline $\begin{array}{c}\text { DoX Loading } \\
\text { capacity }(\%)\end{array}$ & $11.4 \%$ & $11.1 \%$ \\
\hline DLS Size $(\mathrm{nm})$ & $102.4 \pm 3.56$ & $95.8 \pm 8.45$ \\
\hline PDI & 0.10 & 0.11 \\
\hline Zeta $(\mathrm{mV})$ & $-17.35 \pm 2.11$ & $-19.62 \pm 3.8$ \\
\hline IND loading (wt\%) & $19.8 \%$ & $\mathrm{~N} / \mathrm{A}$ \\
\hline Endotoxin level & $<0.1 \mathrm{EU} / \mathrm{mL}$ & $<0.1 \mathrm{EU} / \mathrm{mL}$ \\
\hline
\end{tabular}

D

DOX/IND-Liposome

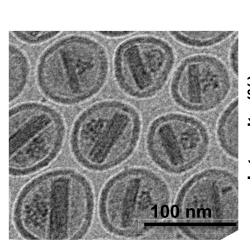

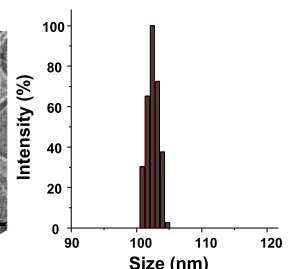

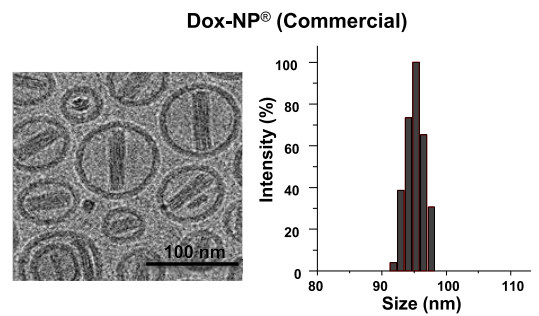

Figure 3. Synthesis of the dual-delivery DOX/IND-Liposome. (A) Schematic to show that the carrier is synthesized by self-assembly of an IND prodrug to form a liposome, which is subsequently loaded with DOX. The synthesis commences by conjugating IND to a single chain phospholipid [1-palmitoyl-2-hydroxy-sn-glycero-3-phosphocholine (PL)] to derive the IND-PL prodrug, as previously described by us. ${ }^{22}$ The three-step synthesis process is schematically depicted in Figure S3. The prodrug is mixed with cholesterol and DSPE-PEG $2 \mathrm{~K}$ to form a lipid film for the construction of liposomes. (B) Schematic to outline the liposome synthesis steps. Briefly, the lipid film comprised of IND$\mathrm{PL}$, cholesterol, and DSPE- $\mathrm{PEG}_{2 \mathrm{~K}}$ at a molar ratio of 70:25:5, was hydrated in a $\left(\mathrm{NH}_{4}\right)_{2} \mathrm{SO}_{4}$ solution, followed by sonication and removal of free $\left(\mathrm{NH}_{4}\right)_{2} \mathrm{SO}_{4}$. DOX was remotely loaded by using a proton gradient, as shown in the bottom panel. $\left(\mathrm{NH}_{4}\right)_{2} \mathrm{SO}_{4}$ dissociates into protons, 
Figure 3. continued

$\mathrm{NH}_{3}$ and $\mathrm{SO}_{4}{ }^{2-}$. DOX is a weak basic molecule that is capable of diffusing across the IND-PL lipid bilayer into the liposome, where it is converted to a (DOX- $\left.\mathrm{NH}_{3}\right)_{2} \mathrm{SO}_{4}$ precipitate, incapable of back diffusion across the lipid bilayer. (C) Side-by-side comparison of DOX/INDLiposome and Dox-NP for drug loading capacity, size, polydispersity, charge, and endotoxin levels $(n=3)$. (D) CryoEM pictures to show the morphological similarity between Dox-NP and IND-Liposome, including the presence of the drug precipitate.

interest in IDO-1 inhibitors for cancer treatment, including BC. ${ }^{43}$

Against this background, we set out to establish whether dual delivery of DOX and an indoximod (IND) prodrug by a liposome can initiate an anti-BC tumor immune response in an orthotopic tumor model. We constructed a phospholipidconjugated IND prodrug that self-assembles into a lipid bilayer encapsulated nanovesicle or liposome. Following remote loading of DOX into the liposome through the use of a proton gradient, the innovative dual-delivery DOX/IND carrier was used to conduct PK, efficacy, and safety studies in a murine orthotopic model that resembles human triple negative breast cancer (TNBC). The ensuing innate and cognitive immune response dramatically reduced primary tumor volume, while also eliminating lung metastases. This treatment effect was further enhanced by treatment with an anti-PD-1 monoclonal antibody (mAb).

\section{RESULTS}

Doxorubicin Is an Effective ICD-Inducing Chemotherapy Agent in Breast Cancer. In addition to being considered as a first-line chemotherapeutic for breast cancer, ${ }^{34}$ the anthracycline drug, doxorubicin (DOX), is a potent inducer of ICD and therefore potentially useful to induce TILs in the $\mathrm{BC}$ tumor microenvironment. ${ }^{44}$ In order to provide proof-of-principle testing for the use of ICD in BC immunotherapy, consensus screening guidelines were used to compare the immunogenic effects of DOX with paclitaxel (PTX), cisplatin (CIS), and oxaliplatin (OX) in a $4 \mathrm{~T} 1$ tumor model. $^{45}$ Multiparameter cellular screening to assess cell surface expression of calreticulin (CRT) (cellular stress), ATP release (autophagy), and nuclear disintegration with HMGB1 release demonstrated that DOX, PTX, and OX are effective ICD inducers in $4 \mathrm{~T} 1$ cells (Figure S1A-D). In contrast, CIS failed to induce the same ICD response parameters. In vivo confirmation of an ICD effect was provided by a vaccination approach in syngeneic Balb/c mice (Figure 2A). This requires subcutaneous injection of dying 4T1 cells exposed for $24 \mathrm{~h}$ to DOX $(5 \mu \mathrm{M})$ or PTX $(5 \mu \mathrm{M})$ in one flank of the animals on two occasions, 1 week apart. The animals were rechallenged by injection of live 4T1 cells in the contralateral flank 7 days later (Figure 2). This demonstrated that whereas vaccination with DOX- or PTX-treated cells could significantly suppress tumor growth at the challenged site, CIS $(100 \mu \mathrm{M})$ had no effect (Figure 2 and Figure S1E). In addition to the growth inhibitory effect of the vaccination procedure, we confirmed that the effect is immune mediated by demonstrating perforin and granzyme B-mediated cytotoxic T-cell killing at the tumor site, with increased expression of $\mathrm{CD}^{+} \mathrm{T}$-cells and an increase in $\mathrm{CD} 8 /$ Treg ratios (Figure $\mathrm{S} 1 \mathrm{~F}-\mathrm{H})$.

Synthesis of a Liposomal Carrier for Dual Delivery of DOX and IND. In spite of the promising ex vivo ICD-inducing effects of DOX, our preliminary data demonstrate that IV administration of the free drug failed to induce CRT expression at the site of orthotopic 4T1 tumors (see Figure
9B). As it is known that the encapsulated DOX delivery in PEGylated liposomes improves the PK and treatment efficacy in malignancies such as Kaposi's sarcoma, ovarian carcinoma, and $\mathrm{MBC},{ }^{38,40,46}$ we asked whether it is possible to improve ICD at the BC tumor site through the use of a DOX-only liposome, Dox-NP (identical composition as Doxil for preclinical research use), as well as a dual-delivery liposomal carrier for DOX plus the IDO-1 inhibitor, IND. Contemporaneous targeting of IDO-1 is appropriate in light of its overexpression at the $\mathrm{BC}$ tumor site (including $4 \mathrm{~T} 1$ orthotopic tumors, as shown in Figure S2) and synergy with ICD in a PC model. The first step toward constructing a dual-delivery carrier was the covalent conjugation of IND (I-methyl-Dtryptophan or 1-D-MT) to 1-palmitoyl-2-hydroxy-sn-glycero-3phosphocholine (PL) to form an IND-PL prodrug, as schematically explained Figure $3 \mathrm{~A}$ and Figure S3A. ${ }^{22}$ INDPL self-assembles into a liposome (Figure 3A), which is constructed as outlined in Figure $3 \mathrm{~B}^{22}$ This requires mixing and suspension of IND-PL, cholesterol, and DSPE-PEG $\mathrm{P}_{2 \mathrm{~K}}$ in an organic solvent, which is evaporated from the bottom of a round-bottom flask to form a uniform lipid film. Various molar ratios of IND-PL, cholesterol, and DSPE-PEG ${ }_{2 \mathrm{~K}}$ were tested to obtain optimal lipid bilayer stability and carrier size (Figure S4). Optimal results were obtained using a molar ratio of 75:20:5 for IND-PL, cholesterol, and DSPE-PEG $2 \mathrm{~K}$, respectively. To accomplish remote DOX loading, the protonating agent, $\left(\mathrm{NH}_{4}\right)_{2} \mathrm{SO}_{4}$, was introduced on top of the biofilm, followed by probe sonication and purification across a PD-10 column. The $\left(\mathrm{NH}_{4}\right)_{2} \mathrm{SO}_{4}$-loaded IND-Liposomes were subsequently incubated in a $\mathrm{DOX} \cdot \mathrm{HCl}$ solution to allow amphiphilic DOX to be imported across the liposomal membrane (Figure 3B, bottom panel). Drug protonation leads to the formation of an intraliposomal (DOX- $\left.\mathrm{NH}_{3}\right)_{2} \mathrm{SO}_{4}$ precipitate, which is incapable of back-diffusion across the lipid bilayer. The combined synthesis process yielded a dual-delivery carrier with IND and DOX loading capacities (w/w) of 19.8 and $11.4 \%$, respectively, as determined by UPLC-MS/MS. This is equivalent to an IND/DOX molar ratio of 4.3:1. Comprehensive liposome characterization demonstrated a carrier of $100 \mathrm{~nm}$ (DLS) size, a low polydispersity index, and a slight negative surface charge (Figure 3C). The liposome maintains its stability and size for up to one month in DI water, PBS, and 10\% FBS-containing RPMI-1640 (Figure S4B). Noteworthy, ultrastructural viewing of the DOX/IND-Liposome by cryo electron microscopy showed a carrier that morphologically resembles Doxil ${ }^{47}$ as well as Dox-NP (Figure $3 \mathrm{D})$, in addition to similarities in their drug loading capacities, size, and charge (Figure 3C). Both formulations had endotoxin levels of $<0.1 \mathrm{EU} / \mathrm{mL}$.

Dual-Delivery Liposome Improves the PK of Drug Delivery and Tumor Drug Concentrations in a 4T1 BC Model. The PK and drug biodistribution of the dual-delivery carrier was assessed in an orthotopic BC model. This model was established by injecting luciferase-transfected $4 \mathrm{~T} 1$ cells into the right second mammary fat pad in Balb/c mice (Figure 4A). ${ }^{48}$ The animals develop rapidly growing primary breast 
A
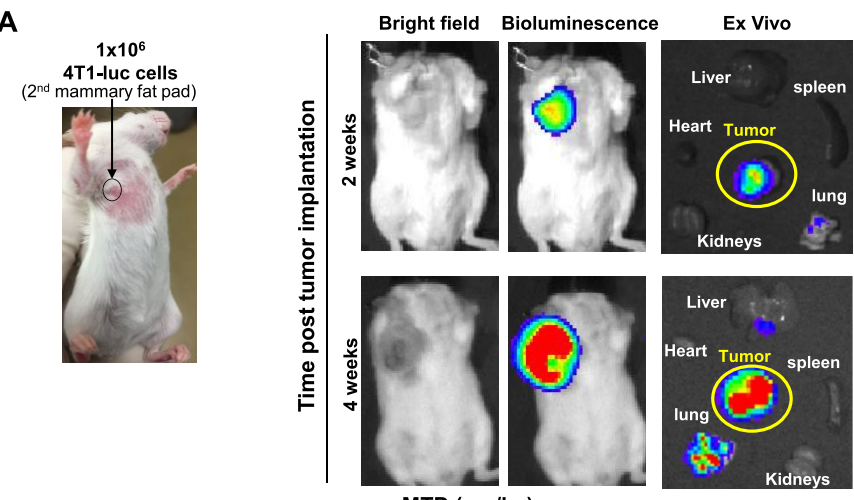

B

$\operatorname{MTD}(\mathrm{mg} / \mathrm{kg})$

\begin{tabular}{c|c|c}
\hline DOX & Dox-NP $^{\circledR}$ & DOX/IND-Liposome \\
\hline 8 & 15 & 15 \\
\hline
\end{tabular}

C
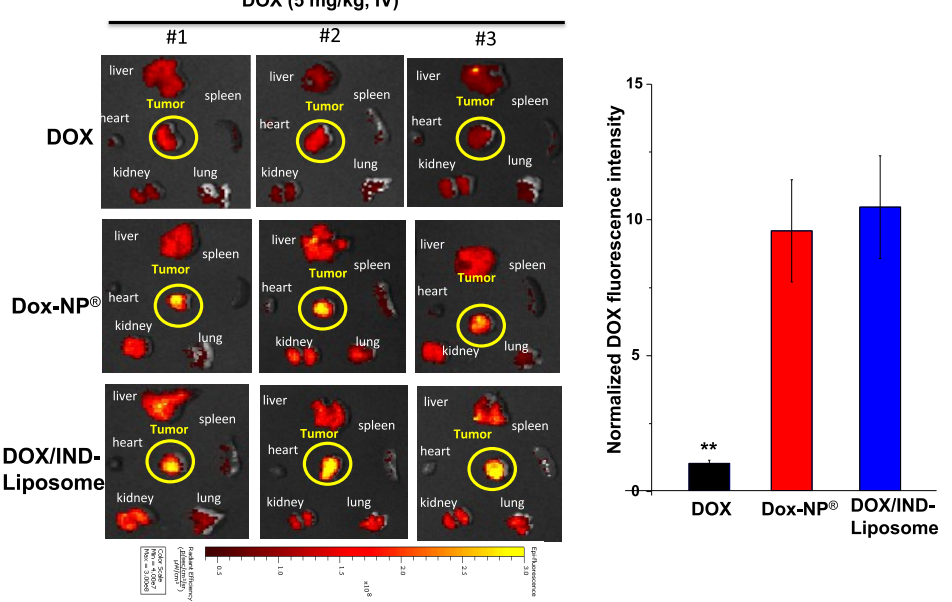

D
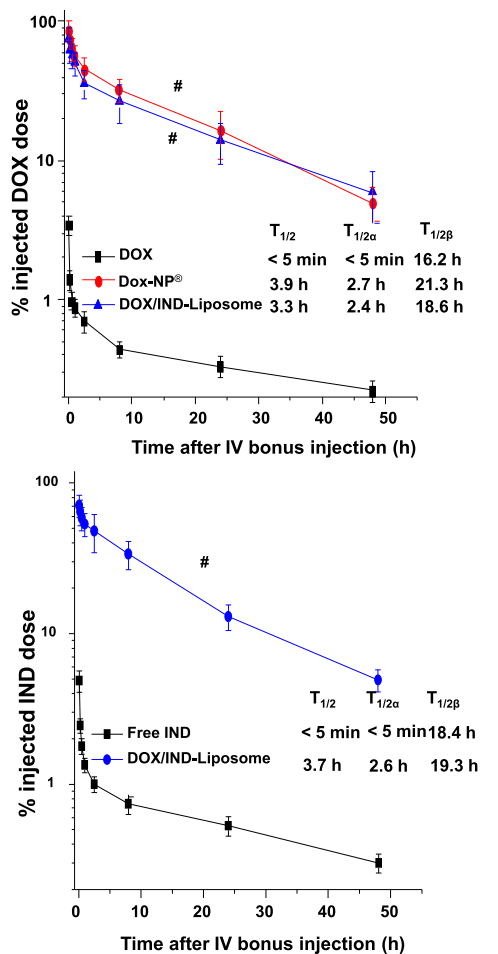
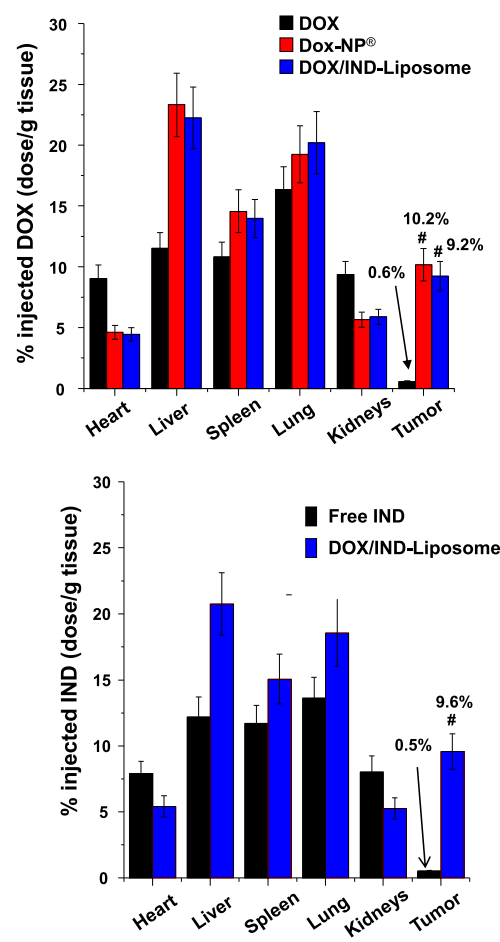

Figure 4. Pharmacokinetics (PK) of drug delivery by the DOX/IND-Liposome compared to Dox-NP in an orthotopic tumor model. (A) Syngeneic orthotopic model was established injecting luciferase-transfected $4 \mathrm{~T} 1$ cells into the 2nd mammary fat pad of Balb/c mice (left). This is followed by the development of a primary tumor mass that can be viewed by IVIS imaging after 2 weeks. Animal sacrifice and collecting the tumors and organs confirmed the treatment effect on primary tumor mass as well as the presence of metastatic nodules in the lung. After 4 weeks, it was possible to visualize the large primary tumor mass and extensive lung metastases. (B) Drug dose calculations for 
Figure 4. continued

the animal studies (first $n=2$, then $n=6$, refer to the Methods section): maximum tolerated dose (MTD) calculations were carried out for the DOX formulations shown, using a NCI protocol. ${ }^{49}$ (C) IVIS imaging of DOX fluorescence at the 4T1 orthotopic tumor site $(n=3)$. Three animals in each group received free DOX, Dox-NP, and the DOX/IND-Liposome at $5 \mathrm{mg} / \mathrm{kg}$ DOX IV. ${ }^{35-37}$ The mice were sacrificed after $24 \mathrm{~h}$ for IVIS imaging. DOX fluorescence intensity was quantified by Living Image software. (D,E) PK and tissue drug distribution in 4T1 orthotopic tumor-bearing mice $(n=6)$, receiving IV injection of free DOX, Dox-NP, and DOX/IND-Liposome at a DOX equivalent dose of $5 \mathrm{mg} / \mathrm{kg}$. Panel D depicts the WinNonlin software calculation of the plasma concentration, expressed as the \% of the injected DOX dose at the indicated time points (left panel). The corresponding tumor and tissue drug concentrations, expressed as \% injected DOX dose/g tissue, appears in the right panel. The equivalent data for IND appears in panel E. Results are expressed as mean \pm SD; $* * p<0.01$ (ANOVA).

tumors that can be detected by IVIS imaging within 2 weeks. This was followed by tumor metastasis to the lung within 30 days postimplantation. ${ }^{48}$ In order to determine a relevant and safe DOX dose for in vivo use, we first assessed the maximum tolerated dose (MTD) of free DOX, the DOX/IND-Liposome, and Dox-NP by a National Cancer Institute protocol, as described in the Methods section. ${ }^{49}$ The MTD in Balb/c mice was calculated as 8,15 , and $15 \mathrm{mg} / \mathrm{kg}$ for DOX, Dox-NP, and DOX/IND-Liposome, respectively. As Doxil is usually injected as an IV dose of $50 \mathrm{mg} / \mathrm{m}^{2}$ in patients, ${ }^{50}$ we used this as the basis to calculate an IV animal dose of $5 \mathrm{mg} / \mathrm{kg}$ of DOX in tumor-bearing mice, using dose conversion data. ${ }^{35-37}$

As DOX is a fluorescent drug substance, IVIS imaging was used in the first experiment to monitor the drug fluorescence intensity following a single IV dose of free drug, Dox-NP or the dual-delivery carrier at a DOX equivalent dose of $5 \mathrm{mg} / \mathrm{kg}(n=$ 3) (Figure 4C). Twenty-four hours postinjection, major organs were collected and DOX fluorescence was quantified by Living Image software (PerkinElmer, version 4.5), using an excitation filter of $500 \mathrm{~nm}$ and a DsRed emission filter. Compared to the weak fluorescence intensity of free DOX at the tumor site, there was an approximate $\sim 10$-fold increase in fluorescence intensity in mice injected with the DOX/IND-Liposome or Dox-NP (Figure 4C). This was followed by a comprehensive PK study, in which orthotopic tumor-bearing mice $(n=6)$ were IV injected with free DOX, Dox-NP, and the DOX/INDLiposome to deliver a DOX equivalent dose of $5 \mathrm{mg} / \mathrm{kg}$. Blood was withdrawn at predetermined time points $(0.083,0.25,0.5$, $1,2.5,8,24$, and $48 \mathrm{~h}$ ) and the plasma used for quantitation of the IND and DOX content by UPLC-MS/MS. Data calculation with WinNonlin software demonstrated a significant increase in the plasma $t_{1 / 2}$ and intratumoral levels of both encapsulated DOX preparations compared to the free drug (Figure 4D). Whereas free DOX was rapidly eliminated from the circulation $\left(t_{1 / 2}\right.$ of $\left.<0.083 \mathrm{~h}\right)$ the circulatory $t_{1 / 2}$ was increased to $\sim 3 \mathrm{~h}$ for Dox-NP and the DOX/IND-Liposome. Drug-dose calculation as a $\%$ of the total injected dose, demonstrated that up to $\sim 10 \mathrm{wt} \%$ (dose/g tissue) of the encapsulated DOX could be seen to distribute to the 4T1 tumor site by $48 \mathrm{~h}$, as compared to $\sim 0.6 \%$ for free DOX (Figure 4D). There was also a significant improvement in the circulatory $t_{1 / 2}$ of free IND as a result of liposomal encapsulation (Figure 4D). UPLC-MS/MS measurement of the IND content at the tumor site confirmed an increase from 0.6 to $9.6 \mathrm{wt} \%$ for free versus encapsulated drug delivery (Figure 4E).

Effective Tumor Growth Reduction and Inhibition of Metastases by the DOX/IND-Liposome. A comprehensive study was performed to compare the effect of free DOX with the effect of encapsulated DOX on tumor growth in the orthotopic 4T1 model. In addition, we also compared the result to treatment with the checkpoint blocking antibody, anti-PD-1, as well as combining anti-PD-1 with the dualdelivery liposome. The comprehensive array of treatment groups used in a single large experiment is shown in Table 1.

Table 1. Treatment Groups for the Performance of the Efficacy Experiment ${ }^{a}$

\begin{tabular}{l|c|c|c}
\hline Treatment groups & Fig. 5 & Fig. 6 & Fig. 7 \\
\hline 1. Saline & $\sqrt{ }$ & $\sqrt{ }$ & $\sqrt{ }$ \\
\hline 2. DOX & $\sqrt{ }$ & & \\
\hline 3. Dox-NP & & & \\
\hline 4. IND-Liposome & $\sqrt{ }$ & & \\
\hline 5. DOX + IND-Liposome & $\sqrt{ }$ & & \\
\hline $\begin{array}{l}\text { 6. DOX + anti PD-1 } \\
\text { 7. DOX/IND-Liposome }\end{array}$ & $\sqrt{ }$ & $\sqrt{ }$ & $\sqrt{ }$ \\
\hline $\begin{array}{l}\text { 8. DOX/IND-Liposome } \\
\text { + anti PD-1 }\end{array}$ & & $\sqrt{ }$ & \\
\hline $\begin{array}{l}\text { 9. DOX/IND-Liposome } \\
\text { + anti CD8 }\end{array}$ & & & $\sqrt{ }$ \\
\hline
\end{tabular}

${ }^{a}$ We used nine groups of animals (each including nine mice) to perform a comparative efficacy study in the 4T1 model. For ease of description and to prevent data crowding, the data are displayed for three comparative groupings as outlined in Figures 5-7. Figure 5 addresses the synergy of DOX and IND-PL co-delivery in comparison to Dox-NP. Figure 6 shows the effect of combining the anti-PD-1 antibody with DOX or the dual-delivery liposome, and Figure 7 investigates the effect of anti-CD8 antibody on the immune response to the DOX/IND-Liposome. The experiment was repeated once, in which data were displayed to show animal survival.

For ease of data description, we will provide the data analysis as three groupings, which correspond to Figures 5-7. The first data set, outlined in Figure $5 \mathrm{~A}-\mathrm{E}$ compares 1, saline; 2, free DOX; 3, Dox-NP; 4, IND-Liposome (non-DOX-loaded, selfassembled nanovesicle); 5, DOX + IND-Liposome; and 7, DOX/IND-Liposome. The second data set, outlined in Figure 6A-F, compares 1 , saline; 6, DOX + anti PD-1; 7, DOX/INDLiposome; and 8, DOX/IND-Liposome + anti PD-1. The third data set, discussed in Figure 7A-D, compares 1, saline; 7, DOX/IND-Liposome, with or without the injection of an antiCD8 monoclonal antibody, to determine the effect of CD8 depletion on the immune response. The dose equivalents of DOX and IND were 5 and $8.7 \mathrm{mg} / \mathrm{kg}$ based on an optimal constructed DOX/IND-Liposome (i.e., ratio 4, Figure S4), respectively, using a total of three injections 3 days apart (Figure 5A).

The results in the first comparative grouping demonstrated that the DOX/IND-Liposome was superior to free DOX and 
A
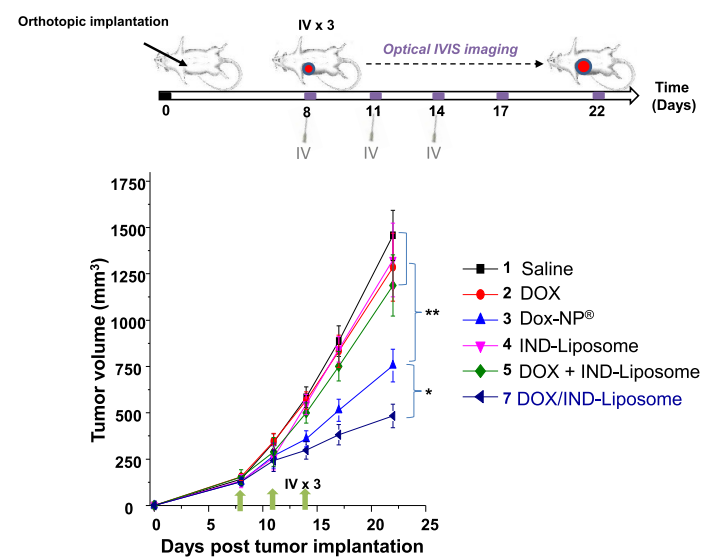

B

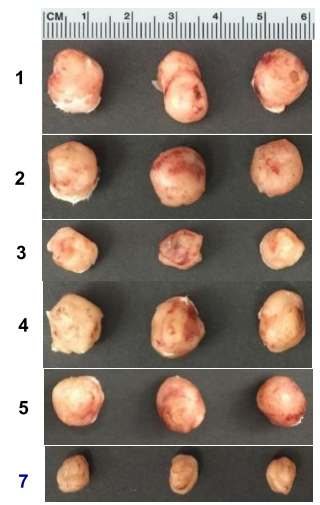

D
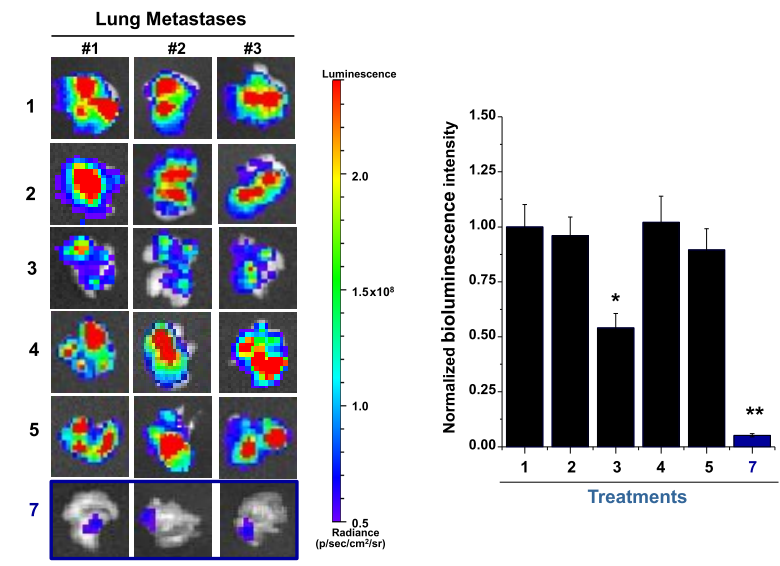

E

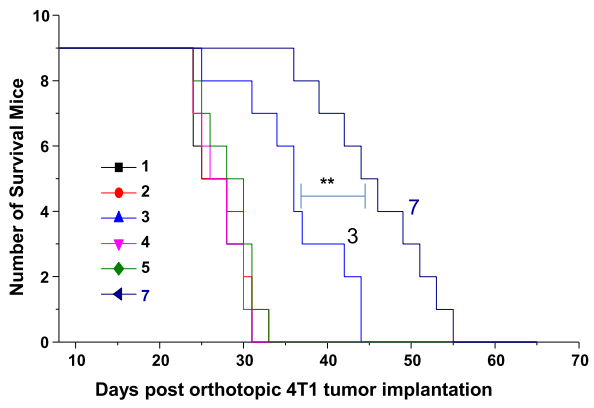

Figure 5. Treatment with the DOX/IND-Liposome impacts tumor growth and metastases in the orthotopic BC tumor model. (A) Outline of the experimental schedule $(n=9)$. The DOX/INDLiposome was IV injected in animals in group 7 on days 8,11 , and 14 to deliver a DOX dose of $5 \mathrm{mg} / \mathrm{kg}$ and an IND dose of $8.7 \mathrm{mg} /$ kg. Treatment was compared to IV injection of saline (\#1), DOX (\#2), Dox-NP (\#3), (non-DOX-loaded) IND-PL-Liposome (\#4), and DOX + IND-PL-Liposome (\#5), using equivalent doses of
Figure 5. continued

DOX or IND. The inhibition of tumor growth by the DOX/INDLiposome is significant compared to Dox-NP $(* p<0.05)$ and other controls $(* * p<0.01$, ANOVA). (B,C) Representative tumor images and average tumor weights after animal sacrifice on day 22 . (D) Representative IVIS imaging and quantification of bioluminescence intensity of lung metastases $(* p<0.05$; $* * p<$ 0.01, ANOVA). (E) Kaplan-Meier analysis to show that the DOX/ IND-Liposome dramatically prolongs animal survival $(n=9$, ** $p<$ 0.01, Log-rank Mantel-Cox test) in a separate experiment.

Dox-NP $(p<0.05)$ in shrinking primary tumor size (Figure $5 \mathrm{~A}-\mathrm{C})$. Moreover, IND-PL enhanced the reduction in tumor size when co-delivered with DOX, but had no effect by itself or when combined with free DOX. Noteworthy, Dox-NP had a statistically significant effect $(p<0.01)$ compared to that with treatment groups, other than the dual-delivery liposome. Evidence that the reduction in tumor size by encapsulated DOX is due to an immunogenic effect with innate and cognate immune features, is discussed in Figures 8 and 9. In order to determine what effect treatment had on metastatic spread to the lung, ${ }^{48}$ mice were sacrificed on day 22 , and the lungs were harvested for ex vivo IVIS imaging (Figure 5D). Quantitative expression of the imaging intensity demonstrated a highly significant reduction in metastatic spread in response to encapsulated co-delivery of DOX and IND compared to DOX only (Dox-NP). However, Dox-NP did exert a statistically significant effect compared to other treatment groups. A parallel survival study was performed, using nine animals in each group. Kaplan-Meier plots confirmed that the dualdelivery liposome resulted in a significant survival benefit, including in comparison to Dox-NP (Figure 5E).

Antibodies that block the PD-1 and CTLA-4 receptors have been used with great success in soliciting of anticancer immunity in melanoma, NSCLC, and renal carcinoma. ${ }^{51,52}$ In contrast, the effect of immune checkpoint inhibitors in $\mathrm{BC}$ has been disappointing, possibly due to the immune deplete microenvironment in $\mathrm{BC}$, where the absence of TILs as well as the failure to express PD-1 or its ligand may preclude an immune response to checkpoint blocking antibodies. ${ }^{12,13}$ As ICD may trigger an immune response that can be boosted by treatment with anti-PD-1, an antibody from the anti-PD clone, RMP1-14 (BioXcell), was administered intraperitoneally (IP) at $100 \mu \mathrm{g} /$ mouse on day 8,11 , and 14 . Immunohistochemistry (IHC) confirmed PD-1 expression at the 4T1 BC tumor site (Figure 6A). Assessment of tumor size showed a significant reduction of tumor volume in the animals receiving combined treatment with the DOX/IND-Liposome plus the anti-PD-1 antibody (Figure 6B-D). In addition, there was a total disappearance of lung metastases using the combination therapy (Figure 6E). Strikingly, the addition of the antibody was also responsible for significant further improvement in survival outcome, as demonstrated by Kaplan-Meier analysis (Figure 6F)

DOX/IND-Liposome Induces Synergistic and Effective Innate and Adaptive Anti-BC Immune Responses in an Orthotopic Model. In order to demonstrate the involvement of the immune response in the growth inhibitory effects of the dual-delivery liposome at the primary tumor site, we asked whether the depletion of $\mathrm{CD} 8^{+} \mathrm{T}$-cells will affect treatment outcome. An anti-CD8 monoclonal antibody was IP administered 3 days prior to the first treatment with the 

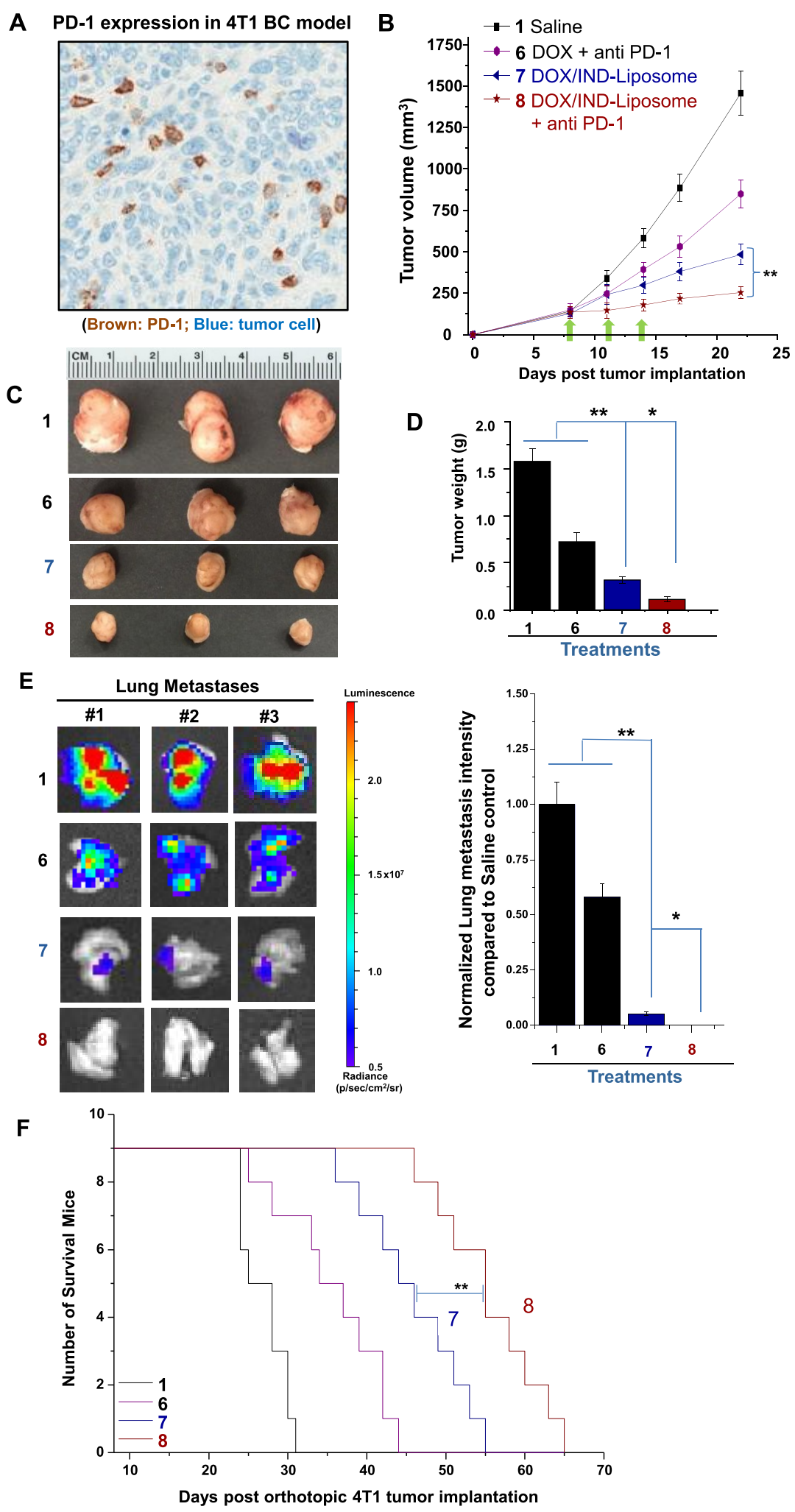

Figure 6. Anti-PD-1 coadministration with the DOX/IND-Liposome augments growth inhibition and eradication of lung metastases. Green arrows represent the treatment time points including DOX formulations and/or anti PD-1. (A) IHC staining showing pronounced PD-1 expression in the 4T1 BC tissue. (B) Tumor growth was assessed as in Figure 5, demonstrating that the addition of anti-PD-1 (injected IP at $100 \mu \mathrm{g} /$ mouse on days 8,11 , and 14) exerted additional growth inhibitory effects $(n=9, * * p<0.05$ ANOVA). (C,D) Representative tumor images and tumor weights for the treatment groups. (E) Representative IVIS images and quantitative data to show the complete disappearance of lung metastases in animals receiving coadministration of anti-PD-1. (F) Kaplan-Meier analysis to show prolonged animal survival by anti-PD-1 administration $(* * p<0.05$, Log-rank Mantel-Cox test) in a separate experiment $(n=9)$. 
A

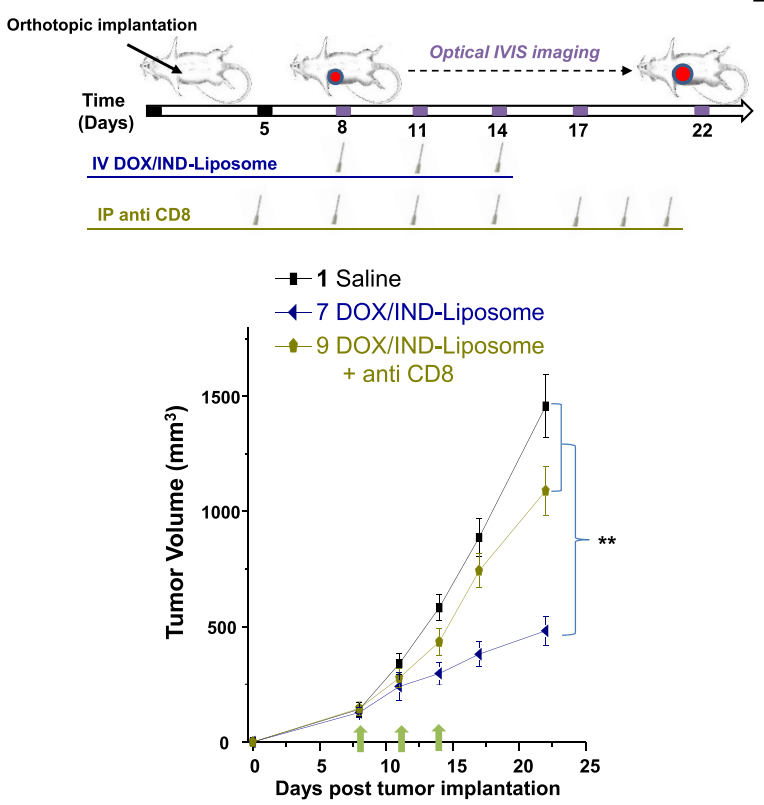

B

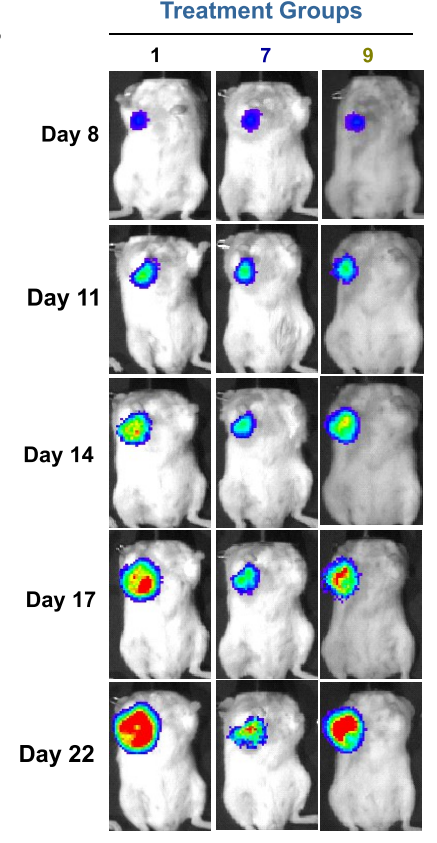

C
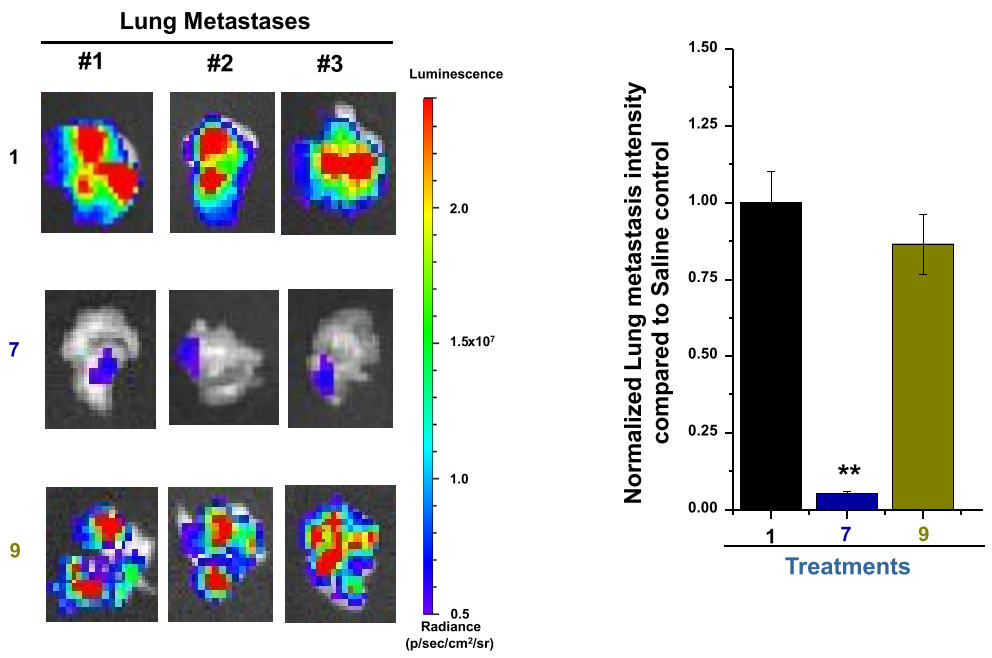

D

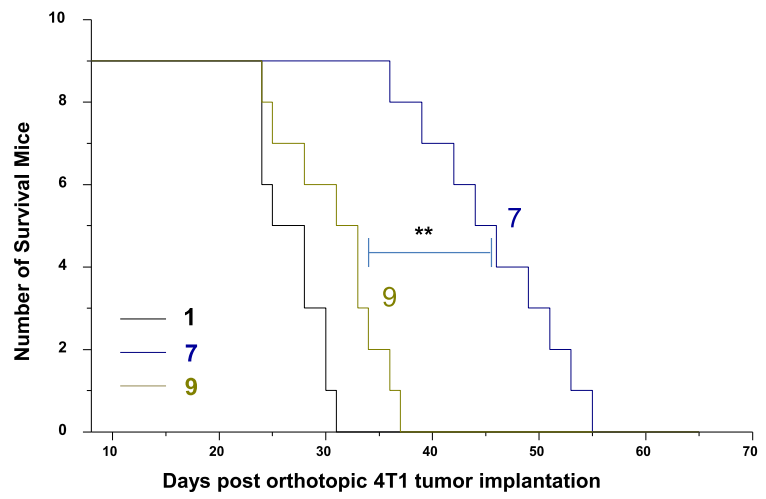

Figure 7. Anti-CD8 monoclonal antibody interferes in the antitumor efficacy of the DOX/IND-Liposome. In order to demonstrate the critical role of cytotoxic $\mathrm{CD8}^{+} \mathrm{T}$-lymphocytes in antitumor immunity, anti-CD8 monoclonal was IP injected in treatment group 9, 3 days prior to the first drug administration and repeated every 2-3 days until the termination of the study. (A) Comparative tumor growth inhibition as described in Figure $5(n=9)$. (B) IVIS imaging data align with the growth inhibitory effects. (C) Representative ex vivo IVIS imaging, with quantification of luciferase expression, to show interference of anti-CD8 on lung metastatic spread. (D) Kaplan-Meier analysis to show that CD8 depletion dramatically reduces animal survival. Results are expressed as mean \pm SD $(n=9, * * p<0.01$, ANOVA). 

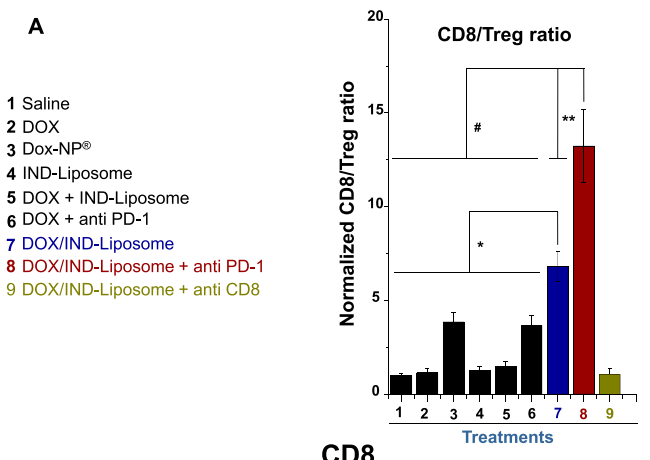

B

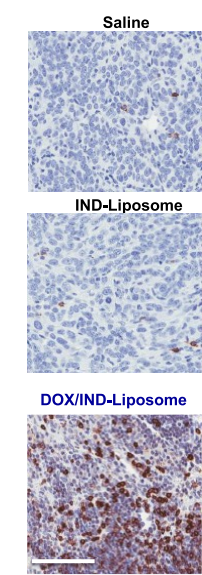

C
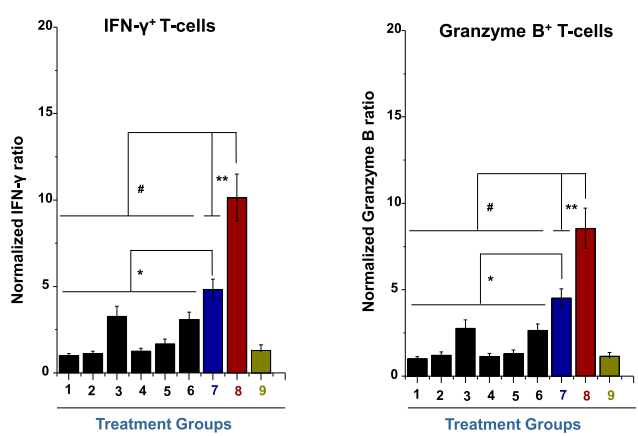

D

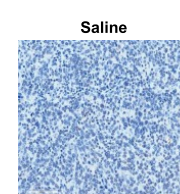

Perforin

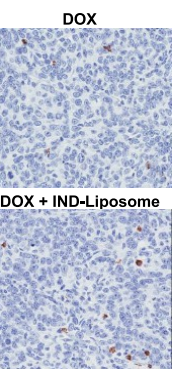
DOX/IND-Lip
+ anti PD-1
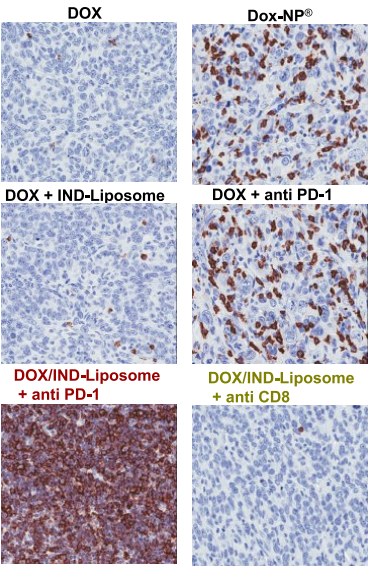
+ anti CD8

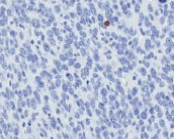

Treatment Groups
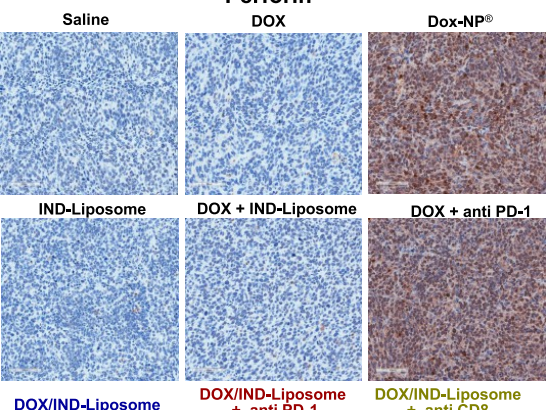

DOXIND-Liposom
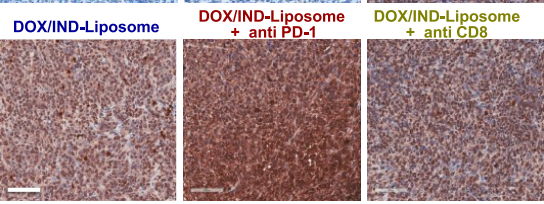

Figure 8. Immune phenotyping to demonstrate the effect of the DOX/IND-Liposome on initiating adaptive anti-BC immunity. Tumors were harvested from the different animal groups depicted in Table 1 to perform IHC staining and flow cytometry. (A) Multicolor flow cytometry analysis to show the impact on CD8/ Treg ratios $(n=9)$. (B) IHC staining for CD8 expression in tumor tissue sections. (C) Flow cytometry analysis of T-cell IFN- $\gamma^{+}$ expression in a $\mathrm{CD} 45^{+} \mathrm{CD}^{+} \mathrm{CD}^{+} \mathrm{IFN}-\gamma^{+}$gated cell population;
Figure 8. continued

granzyme $\mathrm{B}^{+}$expression in a $\mathrm{CD}^{+} 5^{+} \mathrm{CD} 3^{+} \mathrm{CD}^{+}$granzyme $\mathrm{B}^{+}$gated cell population. (D) IHC staining for perforin expression. Additional IHC and flow data for the expression of FOXP-3, CC-3, IL12p70, and LC-3 are shown online (Figure S5C-E,G). The general treatment effect for the dual-delivery liposome (group 7) was to trigger effective cytotoxic killing at the tumor site, with significant boosting of the response by anti-PD-1 (group 8), and response decline during anti-CD8 administration (group 9).

liposome, and repeated every 2-3 days (group 9, Table 1). When compared to the response in group 7, which was treated with the DOX/IND-Liposome alone, we observed that the depletion of $\mathrm{CD}^{+}$T-cells (confirmed by IHC in Figure $8 \mathrm{~B}$ ) could dramatically interfere in the growth inhibitory effects of the liposome at the primary tumor site as well as the disappearance of metastases (Figure 7A-C). Anti-CD8 administration also interfered in survival outcome (Figure 7D). These findings are indicative of the generation of a CTL mediating the anti-BC immune response. Anti-CD8 administration also significantly reduced the immune response to Dox-NP as well as the DOX/IND-Liposome in Figure S6.

In order to corroborate the above findings, extensive further immune phenotyping was performed on tumors harvested from the treatment groups in Table 1, using IHC staining and multiparameter flow cytometry (Figures 8 and 9). Flow cytometry showed that CD8/Treg ratios were markedly increased in DOX/IND-Liposome-treated mice compared to Dox-NP, which in turn, showed significant differences from other treatment groups (Figure $8 \mathrm{~A}$ ). The CD8/Treg ratio in group 7 was significantly enhanced by treatment with anti-PD1 , whereas the administration of anti-CD8 essentially restored the ratio to values seen in the saline treatment group (Figure $8 \mathrm{~A}$ ). These treatment effects were further corroborated by IHC staining for CD8, which clearly demonstrate the appearance of CTLs in response to DOX and IND codelivery; the numbers were further boosted by the addition of anti-PD-1 (Figure 8B). A diagonally opposite trend was seen during IHC staining for FOXP3 expression, which showed disappearance of Tregs (Figure S5C). The effective induction of a cognate immune response was further corroborated by flow cytometry and IHC results looking at the local production or expression of IFN- $\gamma$, granzyme B, perforin, activated caspase 3 and IL12p70 (Figure 8C,D and Figure S5D,E).

Apart from the impact on adaptive immunity, we also looked at innate parameters that reflect the induction of ICD (Figure 9A,B and Figure S5F,H). This was demonstrated by the dramatic increase in CRT expression as well as the levels of its counter receptor, CD91, on DCs in tumor tissue of animals treated by the dual-delivery liposome (Figure 9A,B). Moreover, the response was further enhanced or reduced by treatment with anti-PD-1 or anti-CD8 monoclonal antibodies, respectively, as described above. Similar responses were seen for biomarkers that reflect dendritic cell activation, including the integrin receptor, CD103 (Figure 9A), that is used by DCs to facilitate the $\mathrm{CD} 8^{+} \mathrm{T}$-cell development and activation, as well as CD80 and CD86 (Figure S5H). We also obtained evidence for increased expression of microtubule-associated protein $1 \mathrm{~A} / 1 \mathrm{~B}$-like chain three (LC-3), which is involved in autophagy and responsible for ATP release during the ICD response (Figure S5G). ${ }^{31,59}$ All considered, these results 

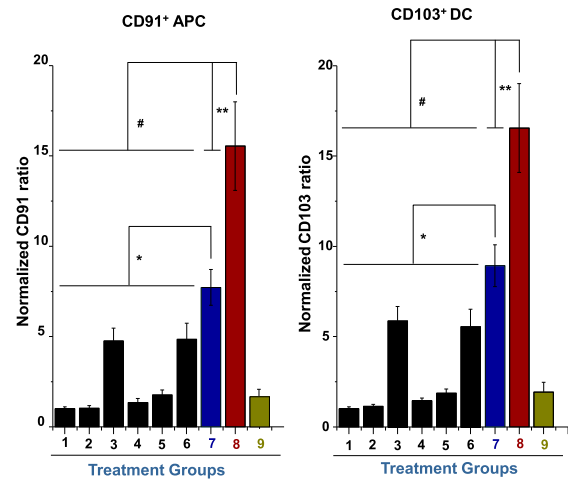

B

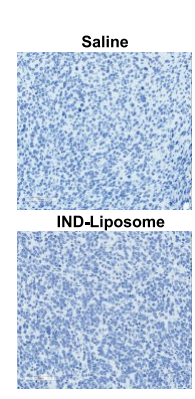

DOXIND-Liposome
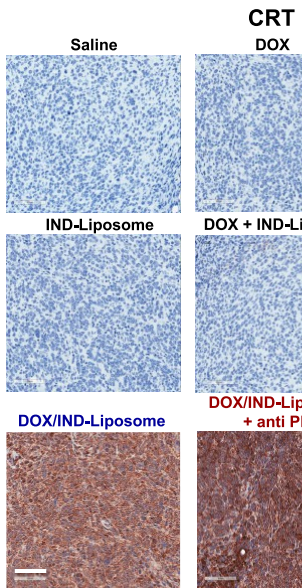

DOX

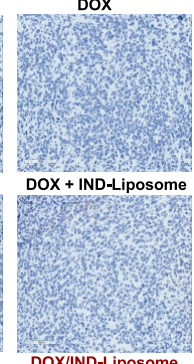

DOX/IND-Liposom
+ anti PD-1
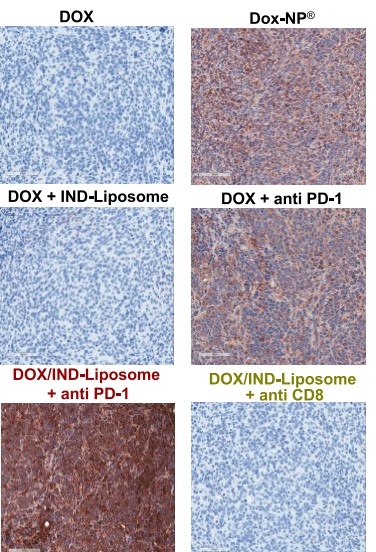

C
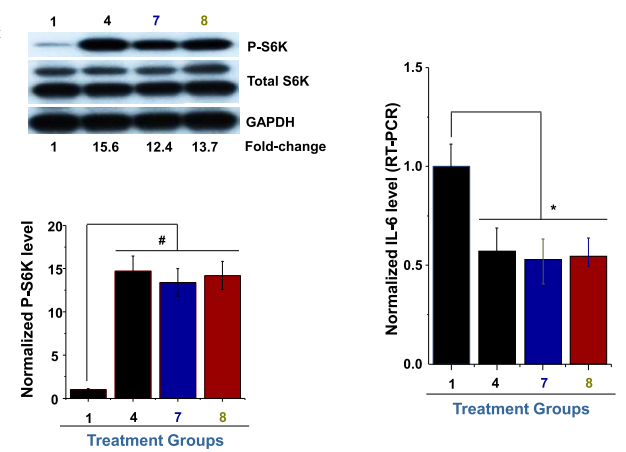

Figure 9. Immune phenotyping to demonstrate the effect of the DOX/IND-Liposome on innate anti-BC immunity. The grouping order in this figure is identical to that of shown in Figure 8A. (A) Multicolor flow cytometry analysis to assess CD91 (CRT binding receptor) and CD103 expression on DCs $(n=9)$. (B) IHC staining to show CRT expression at the primary tumor site. Additional IHC and flow data for the expression of CD91 and CD80/CD86 are shown online (Figure S5F,H). (C) Western blotting to assess phosphorylation (activation) of P-S6 kinase in tumor tissues obtained from animal groups treated with the IND-Liposome ( $n=$ 3 ). The staining intensity of P-S6 kinase in relation to the amount of total kinase protein was graphically expressed by ImageJ software. The right panel shows RT-PCR analysis of IL-6 m-RNA levels at the tumor site. The increased phosphorylation of P-S6 kinase and reduced expression of IL-6 message RNA reflects interference of IND in the local immunosuppressive effects of IDO-1 that is overexpressed at the BC tumor site (Figure S2).

demonstrate synergy between DOX and IND in generating a robust innate immune response at the tumor site.

As it was not logistically possible to include additional treatment groups in the experiment in Table 1, it was necessary to perform an additional study to assess the comparative effect of anti-PD-1 on the response to Dox-NP (Figure S6). This experiment compared the effect of Dox-NP + anti-PD-1 to treatment with saline, anti-PD-1, Dox-NP, the DOX/INDLiposome, and DOX/IND + anti-PD-1. We also compared the outcome to the use of anti-CD8 in the Dox-NP and the DOX/ IND-Liposome groups (Figure S6). The data demonstrate that whereas both the DOX/IND-Liposome and Dox-NP groups benefited from anti-PD-1 administration, the outcome was significantly enhanced in the former treatment group after the first three 3 IV injections (day 17) (Figure S6A,B). The magnitude of this difference was further boosted by the addition of 2 further IV administrations (up to day 24). The use of flow cytometry to perform immunophenotyping of cells harvested from the tumor site confirmed that the increase in the $\mathrm{CD} 8$ /Treg ratios was significantly higher during anti-PD-1 co-treatment in the DOX/IND-Liposome compared to the Dox-NP group (Figure S6D). There was no obvious weight loss or change in AST and ALT enzyme levels in response to any of the treatments (Figure S6C,E). In addition, anti-CD8 administration also significantly reduced the immune response to Dox-NP as well as the DOX/IND-Liposome in Figure S6.

It was possible to discern the effective inhibitory effect of IND-PL on the IDO-1 metabolic pathway at the tumor site by conducting Western blotting to show the phosphorylation status of S6 kinase (Figure 9C, left panel). Activated P-S6 kinase plays a role in the mTOR pathway to reverse the immune suppressive effects of IDO-1 (Figure S2). This corroborates similar effects in 4T1 cells, in which IND-PL dramatically increased the intracellular retention of IND, including an exaggerated effect on S6 kinase phosphorylation (Figure S3B,C). We also observed in assessing IL-6 mRNA expression at the tumor site, that the message abundance was significantly decreased in animals receiving either one of the three IND-containing carriers (Figure 9C, right panel). IL-6 is involved in sustaining IDO-1 expression by an integrated IL-6/ STAT3/AHR autocrine loop, which is disrupted by IND. ${ }^{22,42}$ A similar IND-PL effect was also seen in $4 \mathrm{~T} 1$ cells, where the prodrug dose-dependently interfered in IL-6 release in the cellular supernatant (Figure S3C).

Encapsulated DOX Delivery Improves Drug Safety. One of the major advantages of the PEGylated liposomal DOX formulation has been the improvement of DOX safety. This was confirmed by assessing biomarkers of cardiac, liver, and kidney toxicity in animals that were treated in $4 \mathrm{~T} 1$ orthotopic efficacy study. The results show that the co-delivery liposome is associated with normalization of the increased troponin I, creatine kinase, alanine aminotransferase (ALT), aspartate aminotransferase (AST), and creatinine levels in response to free DOX, similar to Dox-NP (Figure 10).

\section{DISCUSSION}

We demonstrate a chemo-immunotherapy approach for breast cancer, using a dual-drug delivery liposomal carrier that introduces an immunogenic cell death stimulus while, at the same time also interfering in the regionally overexpressed IDO1 pathway that prevents effective T-cell priming. Through innovative design of an IND-PL prodrug that self-assembles into a liposome that can be remotely loaded with DOX, we were able to develop a dual-delivery carrier that could improve the pharmacokinetics of both drugs at the tumor site. Their combined action was to reduce the primary tumor growth as well as interfere in tumor metastases in a syngeneic mouse 
A

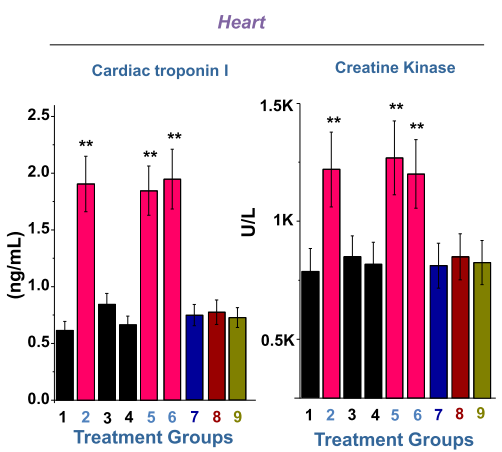

B
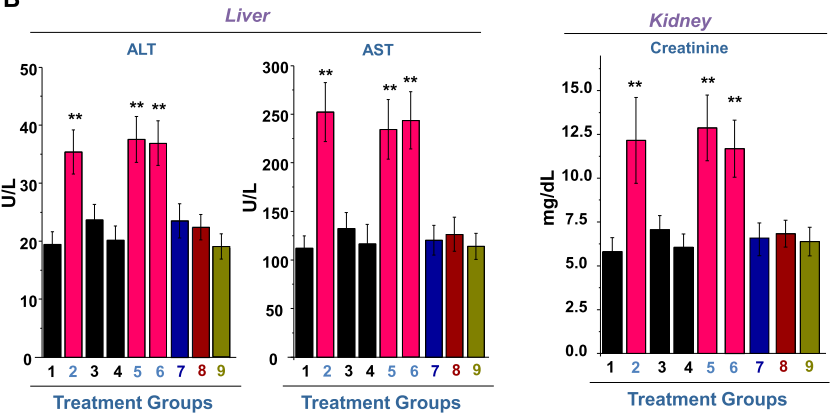

Figure 10. Encapsulated DOX delivery prevents toxicity of the heart, liver, and kidney. Blood was withdrawn on day 22 during performance of the efficacy studies in Figures 5-7 to assess the DOX-related toxicity in the (A) heart (troponin I and creatine kinase), (B) liver (ALT, AST), and kidney (creatinine). Encapsulated DOX delivery by Dox-NP and the DOX/INDLiposome reduced the free drug toxicity. Results are expressed as mean $\pm \operatorname{SD}(n=9, * p<0.05 ; * * p<0.01$, ANOVA $)$.

model (Figures 5-7). The antitumor immune effects were characterized by the expression of ICD biomarkers as well as enhanced dendritic cell and innate immune responses at the tumor site (Figure 9A,B and Figure S5H). Subsequent recruitment and activation of cytotoxic $\mathrm{T}$-cells induced perforin and granzyme B-mediated tumor cell killing, as well as the local production of IFN- $\gamma$ (Figure $8 \mathrm{C}, \mathrm{D}$ ). Immune phenotyping of the tumor tissues confirmed the recruitment of $\mathrm{CD}^{+}$CTLs, disappearance of Treg, and an increase in $\mathrm{CD}^{+} /$ $\mathrm{FOXP}^{+}{ }^{+} \mathrm{T}$-cell ratios (Figure 8A,B and Figure S5C). Not only did the DOX/IND-Liposome provide an improved PK and dual drug delivery effect compared to Dox-NP, but it also eliminated free DOX toxicity in the heart, liver, and kidney (similar to Dox-NP) (Figure 10). We also demonstrated that the dual-delivery liposome could be effectively combined with PD-1 blocking antibodies to eradicate tumor metastases (Figure 6E). This is in keeping with the notion that the generation of ICD in the BC tumor microenvironment introduces an exciting opportunity to improve the response rate to cancer immunotherapy. Problems with the dose and PK of free chemotherapy agents make this a challenging task toward a practical and reproducible approach. Equally important, we demonstrated that improved local delivery of IND constitutes an effective strategy for interfering in the regionally overexpressed IDO-1 pathway, which exerts immunosuppressive effects that are nonredundant with the effect of immune checkpoint inhibitors. All considered, this study demonstrates the value of a nanocarrier that improves the $\mathrm{PK}$ and action of a synergistic drug combination to trigger a robust anti-BC tumor immune response to the primary tumor as well as associated metastases.

The use of chemotherapy to initiate immunotherapy is a logical choice in light of emerging clinical data indicating that neoadjuvant chemotherapy with DOX, docetaxel, cyclophosphamide and taxanes is capable of inducing pathological complete responses due to recruitment of TILs in BC patients. ${ }^{12,13,53}$ In addition, there are also indications that neoadjuvant chemotherapy may have a survival effect compared to adjuvant chemotherapy or surgery in patients with colon or urothelial cancer. ${ }^{54,55}$ It is interesting, therefore, that a number of chemotherapeutics, such as the anthracyclines (DOX, daunorubicin, and mitoxantrone), oxaliplatin, cyclophosphamide, and paclitaxel, can induce a programmed cell death response in tumor cells that is immunogenic in nature. $^{22,28,29,56}$ This ICD response includes the translocation of CRT, which is normally expressed in the endoplasmic reticulum, to the cancer cell surface, where it provides an "eatme" signal for dendritic cell uptake. ${ }^{26,27}$ ICD is also accompanied by the release of the alarmin, HMGB1, at a more advanced stage of cell death, with the ability to induce dendritic cell maturation and tumor antigen presentation through binding to TLR-4. ${ }^{57}$ Moreover, ICD also involves autophagy, which leads to the release of ATP. ${ }^{58,59}$ ATP serves as a danger signal that triggers a purinergic dendritic cell receptor which leads to assembly of the NRLP3 inflammasome and IL- $1 \beta$ production. ${ }^{60-63}$

Although the ICD concept dates back more than a decade, the deliberate use of chemo-immunotherapy has only been pursued in a limited number of animal studies, including in murine lung and colon cancer models. ${ }^{44,64}$ It is also possible to induce ICD through the use of physicochemical stimuli, such as ionizing radiation or photodynamic therapy. ${ }^{65}$ Here, we demonstrate the use of a liposomal carrier to induce ICD at an orthotopic BC tumor site, an outcome that is not accomplishable with free DOX (Figure 9B). We ascribe the tumor-associated ICD effect to increased DOX delivery to the tumor site as a result of the enhanced permeability and retention effect of the nanocarrier. ${ }^{39}$ Our animal PK data of Dox-NP (Figure 4) agrees with the highly significant improvement in the PK and tumor levels of DOX in clinical Doxil treatment studies. ${ }^{39,66-68}$ For instance, the clinical PK studies demonstrate an initial DOX distribution phase with a $t_{1 / 2}$ of $1-3 \mathrm{~h}$, followed by a second distribution phase with a $t_{1 / 2}$ of 20-90 h. ${ }^{39,66-68}$ Moreover, the "area under the curve" for Doxil delivery in human studies is $\sim 300$-fold bigger than the free drug, whereas the clearance and volume of distribution are reduced by factors of 250- and 60-fold, respectively. ${ }^{39,66-68}$ Although Dox-NP was effective in inducing CRT expression and initiating an effective $\mathrm{BC}$ tumor immune response in our animal studies, the efficacy of the response and survival outcome was significantly less than the impact of the DOX/ IND-Liposome (Figures 5-9), even in the presence of antiPD-1. As there was no difference between Dox-NP and the dual-delivery liposome in terms of the $\mathrm{PK}$ and intratumor concentrations of DOX, we ascribe the improved tumor growth and metastasis inhibition by the DOX/IND-Liposome to the action of co-delivered IND (Figures 5A,D). Moreover, the PK of IND-PL was also dramatically improved by encapsulated delivery (Figure 4E), with significant accentuation of $\mathrm{CD}^{+} \mathrm{CTL}$ recruitment (Figure $8 \mathrm{~B}$ ), disappearance of Tregs (Figure S5C), and increase in the CD8/Treg ratios compared to Dox-NP (Figure 8A). These findings are 
congruent with the demonstration that encapsulated IND-PL delivery effectively interfered IL-6 mRNA expression (Figure 9C, right) in parallel with phosphorylated S6 kinase activation (Figure 9C, left). These response outcomes are indicative of interference in the metabolic action of IDO-1, which is overexpressed at the BC tumor site (Figure S2). Cellular data further confirm that the increased uptake and retention of IND-PL exerts a stronger effect on P-S6 kinase and IL-6 production compared to the free IND (Figure S3B). A report was recently published describing the use of a polymeric carrier for the co-delivery of DOX and NLG919 (another IDO inhibitor). ${ }^{69}$ This study demonstrated a redox-responsive immunostimulatory polymeric prodrug micellar carrier for co-delivery of DOX and NLG919 with synergistic antitumor efficacy. However, there was no attempt to study the impact of the treatment on ICD, and this inhibitor (aka GDC-0919) also performed less favorably in two Phase 1 studies. $^{70,71}$ In contrast, there are currently a total of 17 indoximod clinical studies, according to the NIH database (clinicaltrials.gov).

Although it is clear that the dual-delivery carrier yields superior antitumor immune effects compared to Dox-NP, it is uncertain to what extent the improvement is due to the harmonized PK of the drugs, the regional delivery of IND to the site where IDO-1 is overexpressed or a synergistic mechanism of action (Figures 5-7). A case for synergy can be made insofar as the generation of INF- $\gamma$ production by ICD-induced cytotoxic T-cells can induce additional IDO-1 expression and PD-1 ligand expression in a paracrine fashion. This will create a paradoxical increase in the metabolic and immune checkpoint receptor-mediated immune suppression at the same site in the tumor microenvironment where ICD is induced. Thus, inhibition of IDO-1 activity at the same site as ICD induction may be necessary for the effects of ICD to be propagated. Even though neoadjuvant chemotherapy is capable of improving TIL recruitment with a complete pathological response the $\mathrm{BC}$ tumor site, it is difficult to predict in advance which patients will respond. We propose that the improved delivery of the ICD stimulus by a nanocarrier provides a more predictable approach for the implementation of chemoimmunotherapy in terms of biodistribution, and dosimetry considerations. It is also important to consider that even though ICD-inducing drugs (such as DOX) may induce immunogenic effects at the tumor site, the free drug could exert immunosuppressive effects at systemic level to counter the local outcome. In addition to the use of the DOX/IND nanocarrier, it would also be possible to develop custom-design nanocarriers that deliver taxanes (e.g., paclitaxel, docetaxel) or cyclophosphamide to initiate ICD responses for cancer immunotherapy. ${ }^{45}$ It is also possible to include small molecule inhibitors of the IDO-1 pathway other than IND, including epacadostat. ${ }^{72-74}$

Aside from the ability of the DOX/IND-Liposome to serve as a standalone immunotherapy platform for BC, we demonstrate that the antitumor response of the nano-enabled platform can be enhanced by combining the liposome with an anti-PD-1 antibody (Figure 6). This finding could be of significance to a wide range of immune checkpoint inhibitors, which even under the best treatment circumstances (e.g., melanoma and NSCLC), yield response rates of $20-40 \%$ only. $^{75-79}$ Although the exact explanation for the limited response rate is being researched, the current view is that responsiveness to immune checkpoint inhibitors is dependent on the presence of TILs that express immune checkpoint receptors. ${ }^{1,80-83}$ Moreover, there appears to be a requirement for a high burden of nonsynonymous DNA mutations at the cancer site to develop a hot immune microenvironment. ${ }^{10,11}$ These mutations give rise to potent neo-epitopes that are presented to T-cells by class I major histocompatibility complex on antigen-presenting dendritic cells. ${ }^{84-86}$ Although putatively this leads to robust activation of naïve T-cells and the recruitment of TILs, ${ }^{87,88}$ it is difficult to predict in a population of patients who the responders will be. We propose that the guesswork could be diminished by nanocarriers that introduce ICD stimuli in a predictable manner. Moreover, our study show that interference in the IDO-1 pathway is nonredundant with the effect of the PD-1 checkpoint receptor, allowing the DOX/IND-Liposome to be combined with antiPD-1, which further boosts the immune response (Figure 6). We propose that the same treatment effect will also be accomplishable with additional immune checkpoint blocking antibodies, and that a combinatorial approach could also benefit other "cold" solid tumors.

An interesting question regarding the use of ICD to improve immunotherapy is the identity of the tumor-associated antigens that are presented to the cognitive immune system. Theoretically, ICD should allow the presentation of mutational as well as nonmutational tumor antigens, which could expand the clonal diversity of the T-cell response. Antigen proofreading by the T-cell antigen receptors (TCR) could allow the selection of $\mathrm{T}$ cells that could mount an effective immune response to nonmutational antigens. Moreover, the expanded repertoire of responding $\mathrm{T}$ cells could improve $\mathrm{T}$-cell memory, which is important for a durable immune response that controls disease resurgence and development of metastases. $^{86,89-92}$ The robustness of the TCR activation response could also have a bearing on the severe immunological side effects that develop as a result of interference in the regulation of activated $\mathrm{T}$ cells by checkpoint receptors. ${ }^{93-96}$ One possibility is that ICD could lead to a lesser tendency toward an over-reactive immune response by involving less potent nonmutational antigens. ${ }^{97,98}$ This possibility will be investigated in future studies. In addition to the possibility of reducing immunological side effects, the encapsulated delivery of DOX by the dual-delivery liposome was equally effective to Dox-NP in protecting against cardiac, liver, and renal side effects (Figure 10).

In studying a combination of therapies, it is difficult to include a comprehensive series of controls in every experiment due to the logistics and limitation of the number of animals that can be included in a single study. This was illustrated by the necessity to perform a separate experiment (from the data shown in Figures 5-7) to assess the combination of Dox-NP with anti-PD-1 (Figure S6). It was also not possible to independently assess the combination of Dox-NP with IND (either as a free drug or as a separate liposomal form). However, we did demonstrate previously that the combination of chemotherapy (free and encapsulated) with separately administered IND (free and encapsulated) did not achieve the same efficacy as combining the chemotherapy with IND-PL in a single nanocarrier (in pancreas cancer). ${ }^{22}$

\section{CONCLUSION}

In summary, we developed a liposomal chemo-immunotherapy approach for use in BC. The liposome delivers DOX to provide an ICD stimulus as well as an IND prodrug to interfere in the metabolic immunosuppressive effects of the IDO-1 
pathway in the tumor microenvironment. IV injection of the DOX/IND-Liposome favorably improved the PK and tumor uptake of both drugs at the tumor site of a syngeneic 4T1 orthotopic BC model. Compared to the DOX-only liposome, Dox-NP, the dual-delivery carrier significantly enhanced the anti-BC immune response at the primary as well as metastatic tumor sites. The response was further augmented by the addition of an anti-PD-1 monoclonal antibody, demonstrating that the potential use of ICD to generate a "hot" or immune replete $\mathrm{BC}$ tumor microenvironment to increase the number of responders in immunotherapy studies that use IDO inhibitors or immune checkpoint blocking antibodies.

Although the concept of chemotherapy-induced ICD has been described in the literature for a number of years, this concept has not been deliberately pursued as a practical and reproducible immunotherapy principle that can be executed by a FDA-approved drug carrier. Our preclinical data clearly demonstrate the key benefit of dual delivery for an immunological perspective in comparison to free drugs or Dox-NP. This has obvious significance for possible clinical translation in human breast cancer where the use of liposomal carriers has already been approved, without the need to develop a new delivery platform from inception. Our demonstration that such a liposome can be made from a self-assembling, lipid-conjugated IND prodrug also provides significant innovation in how a synergistic drug combination can be accomplished. In summary, we report the innovative use of the triad of liposomal properties that provide: (1) effective co-packaging of an IND prodrug with DOX through self-assembly and drug import; (2) effective regional buildup of DOX and IND at the tumor site, suffice for concurrent ICD induction and immunological modulation; and (3) a combined in vivo effect, providing interference in primary tumor growth and elimination of tumor metastases.

\section{METHODS}

Use of 4T1 Cells To Establish an Orthotopic Tumor Model in Syngeneic Balb/c Mice. The 4T1 cell line was obtained from ATCC and was cultured in complete DMEM, containing 10\% FBS, $100 \mathrm{U} / \mathrm{mL}$ penicillin, $100 \mu \mathrm{g} / \mathrm{mL}$ streptomycin, and $2 \mu \mathrm{mM} \mathrm{L}-$ glutamine at $37{ }^{\circ} \mathrm{C}$ in a $\mathrm{CO}_{2}$ incubator. $4 \mathrm{~T} 1$ represents an aggressive phenotype that is representative of human triple-negative $\mathrm{BC} .{ }^{99}$ In order to visualize tumor growth by bioluminescence imaging, 4T1 cells were stably transfected with a luciferase expressing lentivirus in the vector core facility at UCLA. A total of $1 \times 10^{6}$ cells in $30 \mu \mathrm{L}$ $\mathrm{DMEM} /$ matrigel, $1 / 1, \mathrm{v} / \mathrm{v}$, were injected into the right second mammary fat pad of female Balb/c mice (Charles Rivers), 6-8 weeks old (Figure 3). The orthotopic growing tumor, which mimics stage IV breast cancer in humans, leads to the development of lung metastases after 3-4 weeks. ${ }^{48}$ The mice were housed under pathogen-free conditions, and all animal experiments were approved by the UCLA Animal Research Committee.

Confirmation of Immunogenic Cell Death (ICD) by Cellular Biomarkers. A total of $1 \times 10^{5} 4 \mathrm{~T} 1$ cells were plated in 24-well plates overnight in complete DMEM medium. The culture medium was replenished with cisplatin (CIS), doxorubicin (DOX), paclitaxel (PTX), and oxaliplatin (OX) at the indicated concentrations for $24 \mathrm{~h}$. One hundred microliters of supernatant from each well was obtained to measure HMGB-1 or ATP concentrations, using an HMGB-1 ELISA kit (IBL International $\mathrm{GmbH}$ ) or ATPlite one-step luminescence assay kits (PerkinElmer) according to the manufacturers' instructions. To determine CRT surface expression, 4T1 cells were trypsinized, washed in cold PBS three times, stained with a primary rabbit anti-CRT antibody (Ab2907, Abcam), followed by an Alexa Fluor 680-conjugated goat anti-rabbit IgG antibody for $30 \mathrm{~min}$ at $4{ }^{\circ} \mathrm{C} .{ }^{22}$ The cells were suspended in $500 \mu \mathrm{L}$ of staining buffer (BD
Biosciences), to which $50 \mu \mathrm{g} / \mathrm{mL}$ propodium iodide was added before reading in a LSRII flow cytometer (BD Biosciences). Flow cytometry data were plotted as fold-change in mean fluorescence intensity compared to the PBS control. The experiment was repeated twice. To visualize the CRT translocation to the $4 \mathrm{~T} 1$ cell surface, $1 \times 10^{4} 4 \mathrm{~T} 1$ cells were seeded in Lab-Tek 8-well chamber slides (Thermal Scientific) overnight and then treated with CIS $(100 \mu \mathrm{M})$, DOX (5 $\mu \mathrm{M})$, and PTX $(5 \mu \mathrm{M})$ for $24 \mathrm{~h}$. Cells were fixed in $4 \%$ PFA for 15 min, washed in cold PBS, and stained for 30 min with an Alexa Fluor 647 -conjugated anti-CRT antibody (ab196159, 1/500, Abcam). ${ }^{22}$ The cell surface membrane was visualized by staining with $5 \mu \mathrm{g} / \mathrm{mL}$ Alexa Fluor 488-conjugated wheat germ agglutinin (W32466, 1/200, Thermo Fisher), followed by nuclear staining with Hoechst 33342 (H3570, 1/2000, Invitrogen) before visualization under a Leica SP8SMD confocal microscope $(63 \times$ objective lens).

Assessment of Cellular Indoximod (IND) Content in 4T1 Cells. A total of $1 \times 10^{5}$ cells were seeded in 24-well plates overnight in complete DMEM medium. The cells were treated with free IND or IND-Liposome to deliver a dose equivalent of $100 \mu \mathrm{g} / \mathrm{mL}$ IND for 4 , 24 , and $72 \mathrm{~h}$. Cells were trypsinized, harvested, and dissolved in methanol overnight, before measuring the IND and IND-PL concentrations by UPLC-MS/MS, following our established proto$\mathrm{col}^{22}$

Assessment of the IND Effect on IDO-1 Response Parameters at the Tumor Site. The immunosuppressive effect of IDO-1 involves a number of downstream pathways, including inhibition of the mTOR pathway (Figure S2). In order to determine the impact of encapsulated IND delivery on the activation status of S6 kinase (a component in the mTOR pathway), Western blotting was used to assess total S6K protein as well as the level of kinase phosphorylation (P-S6K) in the tumor lysates. ${ }^{22,100}$ GAPDH was used as a comparative control. Tumors were cut into small pieces and homogenized in RIPA buffer, supplemented with a cocktail of proteinase and phosphatase inhibitors. After centrifugation of the lysates at $12000 \mathrm{rpm}$ for $10 \mathrm{~min}$, equal amounts of protein in the supernatants were loaded onto a 10-20\% Tris-glycine gel (Novex gel, Invitrogen) and then transferred to a PDVF membrane. The membrane was blocked with 5\% BSA/TBST, before incubation with primary and HRP-conjugated secondary antibodies that recognize S6K, P-S6K, and GAPDH. The blots were developed by soaking in ECL substrate (Thermo Scientific). The intensity of each protein band on the film was quantified by ImageJ software. ${ }^{22}$

To measure IL-6 mRNA expression by PCR, total RNA was extracted using TRIzol reagent (Invitrogen), treated with DNase I (Amplication grade, Invitrogen), and reverse transcribed using iScript cDNA synthese kit (Biorad). ${ }^{99}$ Quantitative RT-PCR (qPCR) was performed using $\mathrm{iQ}$ and SYBR Green detection kits (Bio-Rad, Hercules, CA). Primers were TCC ACG ATT TCC CAG AGA AC (forward); AGT TGC CTT CTT GGG ACT GA (reverse) (Invitrogen). PCR was conducted using a $3 \mathrm{~min}$ step at $95{ }^{\circ} \mathrm{C}$, followed by 40 cycles at $94^{\circ} \mathrm{C}$ for $15 \mathrm{~s}, 60^{\circ} \mathrm{C}$ for $30 \mathrm{~s}$, and $72{ }^{\circ} \mathrm{C}$ for $30 \mathrm{~s}$.

ICD Vaccination Screening in Balb/c Mice. The procedure and experimental timeline are delineated in Figure 2. 4T1 cells were treated with PBS, $100 \mu \mathrm{M}$ CIS, $5 \mu \mathrm{M}$ DOX, and $5 \mu \mathrm{M}$ PTX for $24 \mathrm{~h}$. Cell suspensions were collected to confirm CRT surface expression by flow cytometry. Subsequently, $1 \times 10^{6}$ dying $4 \mathrm{~T} 1$ cells in $0.1 \mathrm{~mL}$ of DMEM were administered on two occasions into the right flank of female Balb/c mice $(n=6), 1$ week apart. The same mice received SC injection of healthy $1 \times 10^{6} 4 \mathrm{~T} 1$ cells in $0.1 \mathrm{~mL}$ of DMEM/Matrigel, $1 / 1, \mathrm{v} / \mathrm{v}$ in the left flank, 1 week later. Tumor size was closely monitored every $3-4$ days by a digital caliper, using the formula: size $=\pi / 6 \times$ length $\times$ width $^{2}$. Mice were sacrificed on day 19 , and the tumors were collected for flow cytometry and IHC analysis. The statistical difference between groups was calculated using two-way analysis of variance (SPSS software).

Synthesis of the DOX/IND-Liposome. The stepwise synthesis process is outlined in Figure 3B. The process begins with the synthesis of the IND prodrug, which requires IND conjugation to a phospholipid (PL), as described by us. ${ }^{22}$ This involves three steps: 
(i) protection of the amine group on IND by coupling to di-tert-butyl dicarbonate (Boc anhydride); (ii) conjugating the phospholipid-OH to the IND-COOH by an esterification reaction; (iii) removal of Boc to yield the IND-PL prodrug. Successful synthesis was verified by ESIMS (Figure 3A). The liposome was constructed by preparing $50 \mathrm{mg}$ of a lipid mixture in chloroform, containing 75\% IND-PL, 20\% cholesterol, and 5\% DSPE- $\mathrm{PEG}_{2 \mathrm{~K}}$ (i.e., molar ratio of 15:4:1). An optimal ratio was determined by experimentation with different lipid mixtures (Figure S5). The chloroform solution was added to the bottom of a $50 \mathrm{~mL}$ round-bottom glass flask, followed by rotary evaporation of the solvent. This formed a thin lipid biofilm, which was further dried under a vacuum overnight. The film was subsequently hydrated in $2 \mathrm{~mL}$ of $\left(\mathrm{NH}_{4}\right)_{2} \mathrm{SO}_{4}(123 \mathrm{mM})$ before probe sonication for $30 \mathrm{~min}$, using a $20 / 15 \mathrm{~s}$ on/off cycle at a power output of $32.5 \mathrm{~W}$. The free $\left(\mathrm{NH}_{4}\right)_{2} \mathrm{SO}_{4}$ was removed over a PD-10 column (Sephadex G-25, GE Healthcare) using PBS elution. To obtain uniformly sized liposomes, the suspension was extruded 15 times through a miniextruder (Avanti Polar Lipids), using a polycarbonate membrane (Avanti Polar Lipids) with $100 \mathrm{~nm}$ pore size at $80^{\circ} \mathrm{C}$. To achieve remote DOX loading, the $\left(\mathrm{NH}_{4}\right)_{2} \mathrm{SO}_{4} / \mathrm{IND}$-Liposome solution was incubated with $10 \mathrm{mg} / \mathrm{mL}$ DOX for $30 \mathrm{~min}$ at $65^{\circ} \mathrm{C}$. A further round of purification was carried out over a PD-10 column to obtain DOX/ IND-Liposomes. The liposomes were comprehensively characterized for size, $\zeta$-potential, loading capacity, morphology, and endotoxin level using DLS, UPLC-MS/MS, cryoEM, and the chromogenic LAL assay, respectively. DOX loading capacity was calculated using the reported $^{35,36,101,102}$ formula shown below:

$$
\frac{\text { weight of encapsulated DOX }}{\text { weight of liposome }+ \text { weight of encapsulated DOX }} \times 100 \%
$$

An optimal batch was considered as liposomes with an average size $\sim 100 \mathrm{~nm}$, slightly negative charge and stability for at least one month at $4{ }^{\circ} \mathrm{C}$. The liposomes were stored at $4{ }^{\circ} \mathrm{C}$ in the dark until use.

Calculation of Maximum Tolerated Dose (MTD). The MTDs for free DOX, the DOX/IND-Liposome, and Dox-NP were determined by a National Cancer Institute protocol. ${ }^{49}$ The protocol commences with two Balb/c mice receiving IV administration of a $\mathrm{C} 1$ dose equivalent of $2.5 \mathrm{mg} / \mathrm{kg}$ DOX. This is followed by incremental drug administration, using a dose escalation factor of 1.8 until the death of the animals in $<24 \mathrm{~h}$ (aka the Cn dose). Subsequently, the Cn-1 dose was used with a 1.15 escalation factor $(n=2)$ to reach the MTD, which is characterized by the absence of morbidity or mortality. MTD was further corroborated in 6 healthy mice, which received IV injection at the calculated dose. These animals were closely monitored for 15 days, with the stipulation of $<15 \%$ weight loss without morbidity and mortality.

Assessment of the Pharmacokinetics (PK) and Biodistribution of Free and Encapsulated Drugs. The experiment was carried out in $4 \mathrm{~T} 1$ orthotopic tumor bearing mice. To assess the biodistribution of free DOX, Dox-NP, and DOX/IND-Liposome, these formulations were injected IV, at a dose equivalent of $5 \mathrm{mg} / \mathrm{kg}$ DOX $(n=3)$. Twenty-four hours post-administration, mice were sacrificed and ex vivo DOX fluorescence images were obtained for tumor tissue, heart, liver, spleen, lung, and kidneys, using an IVIS imager $($ excitation filter $=500 \mathrm{~nm}$; emission filter $=$ DsRed $)$. Tissue autofluorescence was established at $\mathrm{t}=0$, before the drug injections. DOX fluorescence intensity was obtained by Living Image software (PerkinElmer, version 4.5). In the performance of the PK study, tumor-bearing mice $(n=6)$ received a single IV injection of free DOX, Dox-NP, and the DOX/IND-Liposome at a DOX dose equivalent of $5 \mathrm{mg} / \mathrm{kg}$. At $0.08333,0.25,0.5,1,2.5,8,24$, and $48 \mathrm{~h}$ post-IV injection, $50 \mu \mathrm{L}$ of blood was drawn to obtain plasma for assessment of IND and DOX concentrations by UPLC-MS/MS analysis. In a separate study, tumor tissues, heart, liver, spleen, lung, and kidney were harvested $24 \mathrm{~h}$ post-IV administration and digested for $48 \mathrm{~h}$ in methanol to determine IND and DOX levels by UPLCMS/MS. ${ }^{22,35,103}$ To quantify DOX, the following UPLC-MS/MS conditions were used: C18 Column (130 A, $1.7 \mu \mathrm{m}, 2.1 \mathrm{~mm} \times 50$ $\mathrm{mm})$, connected to Waters LCT Premier with ACQUITY UPLC and
Auto sampler; gradient elution sequence: (i) 0-4 min, 95\% water $+5 \%$ acetonitrile; (ii) $4-6.5 \mathrm{~min}, 5 \%$ water $+95 \%$ acetonitrile; and (iii) $6.5-10 \mathrm{~min}, 95 \%$ water $+5 \%$ acetonitrile. The flow rate was 0.4 $\mathrm{L} / \mathrm{min}$. The $t_{1 / 2}$ of DOX formulations was calculated for display as a noncompartmental as well as a two-compartmental model, using WinNolin software. $22,104,105$

Therapeutic Efficacy Studies Using the DOX/IND-Liposome. These experiments were carried out by injecting luciferase-expressing 4T1 cells in the mammary pad, as described above. The animals were randomly assigned to nine groups (nine animals each) at this stage when the tumor sizes approached $100-150 \mathrm{~mm}^{3}$ ( $\sim$ day 8 days postimplantation). One group of animals (group 7) received IV injection with the DOX/IND-Liposome to deliver a dose of $5 \mathrm{mg} / \mathrm{kg}$ DOX and $8.7 \mathrm{mg} / \mathrm{kg}$ IND on days 8,11 , and 14 (Table 1). Other treatment groups included animals receiving saline or free DOX, Dox$\mathrm{NP}$, the IND-Liposome only, or free DOX + IND-Liposome at similar doses and administration frequency. We also tested whether intraperitoneal (IP) injection of an antimurine PD-1 monoclonal antibody (mAb clone: RMP1-14, BioXcell) on days 8,11 , and 14 will impact the treatment response to free DOX or the DOX/INDLiposome. In order to demonstrate the role of cytotoxic T-cells in the antitumor response, we also assessed the effect of IP administration of $200 \mu \mathrm{g}$ of an anti-CD $8 \alpha \mathrm{mAb}$ (clone 53-6.72, $200 \mu \mathrm{g} / \mathrm{mouse}$, BioXcell) in animals receiving injection with the DOX/INDLiposome. Treatment with the mAb commenced 3 days prior to the first IV injection of the DOX/IND-Liposome, and was repeated every 2-3 days until the end of the study. CD8 T-cell depletion was confirmed by immunohistochemistry (IHC).

Tumor development was carefully monitored by a digital caliper on days $8,11,14,17$, and 22 . Additionally, we visualized the tumor burden by IVIS imaging, following injection of $75 \mathrm{mg} / \mathrm{kg}$ D-Luciferin IP. We also assessed the tumor weight after tissue harvesting from euthanized animals. This included the collection of lung tissue for ex vivo imaging of metastatic spread, which was quantified by bioluminescence intensity in the region of interest, using Living Image software (PerkinElmer, version 4.5). The tumor tissues were also subdivided for performance of flow cytometry, IHC analysis, Western blotting and RT-PCR for IL-6 mRNA. Blood was withdrawn for the measurement of cardiac enzymes (troponin I and creatine kinase), liver enzymes (ALT and AST), and creatinine levels (renal function). In order to determine survival outcome, the animal efficacy study was repeated in a separate study, using the same treatment groups $(n=9)$ and procedures. The survival data were displayed as Kaplan-Meier plots. The criteria for animal sacrifice during KaplanMeier analysis included animal death or moribund status. Moribund status, as defined by our approved animal protocol, reflects lack of activity (unresponsive or unaware to appropriate stimuli), severe (>15\%) body weight loss, lack of stool production, and severe dehydration.

Immunohistochemistry. In order to visualize the phenotypic changes in the immune system of the treated groups, IHC analysis of tumor slices was undertaken to visualize CD8, FOXP-3, CRT, CD91, IL12p70, activated caspase 3 (CC-3), LC-3, and IDO-1 expression, as previously described by us. ${ }^{22}$ Tumor chunks were fixed in $10 \%$ formalin, paraffin embedded, and sliced into $4 \mu \mathrm{m}$ sections, which were mounted on glass slides in the UCLA Jonsson Comprehensive Cancer Center Translational Pathology Core Laboratory. The slides were deparaffinized and incubated in 3\% methanol-hydrogen peroxide, prior to immersing in $1 \mathrm{mM}$ sodium citrate $(\mathrm{pH} 6)$ or 10 mM EDTA ( $\mathrm{pH} 8$ ) at $95{ }^{\circ} \mathrm{C}$ in Decloaking NxGen Chambers (Biocare Medical, DC2012). Following rinsing in PBS containing 0.05\% Tween-20 (PBST), the slides were overlaid with the different primary antibodies for $1 \mathrm{~h}$, followed by addition of the corresponding HRP-conjugated secondary antibodies at room temperature for 30 min. For visualization of different immune cells, the slides were incubated with Vulcan Fast Red Chromogen Kit 2 (Biocare Medical, FR805) or DAB (3,3'-diaminobenzidine). After being rinsed in tap water, the slides were counterstained by Harris' hematoxylin, dehydrated in ethanol, and mounted with media prior to scanning in an Aperio AT Turbo digital pathology scanner (Leica Biosystems). 
For PD-1 staining, slides were baked in $65^{\circ} \mathrm{C}$ oven for $1 \mathrm{~h}$ and were then deparaffinized in xylene and rehydrated through graded ethanols to water. Heat-induced epitope retrieval was performed in a pressure cooker with high $\mathrm{pH}$ buffer (Leica Bond ER2 retrieval solution). Slides were cooled and washed with Leica Bond wash buffer and loaded onto Shandon Sequenza staining system. Leica Bond protein block was applied to slides for $5 \mathrm{~min}$, and then primary anti-mouse PD-1 antibody was applied and incubated in refrigerator overnight. In the morning, slides were rinsed in Bond Wash buffer, and the remaining detection steps were performed on the Leica Bond III using bond refine detection reagents (anti-rabbit polymer, $\mathrm{H}_{2} \mathrm{O}_{2}$ quenching, $\mathrm{DAB}$, and hematoxylin). Slides were then dehydrated through ethanols to xylene and coverslipped, and subsequently scanned by Aperio AT Turbo digital pathology scanner (Leica Biosystems). The slides were read by a veterinary pathologist. The following reagents were used. Primary antibodies: anti-CD8 (\#14-0808, 1/100), and antiFOXP3 (\#13-5773, 1/200) were from eBioscience; anti-CRT (ab2907, 1/50), anti-LRP1(CD91) (ab92544, 1/50), antiperforin (ab16074, 1/100), and anti-PD-1 (ab214421, 1/1000) were from Abcam; anticleaved caspase 3 antibody (\#9664, 1/200) was from Cell Signaling; anti-IFN- $\gamma$ (NBP1-19761, 1/200) and anti-IL12p70 (NBP1-85564, 1/100) were from Novus Biologicals; anti-LC-3 (0231-100/LC3-5F10, 1/100) was from Nanotools; anti-IDO (\#122402, 1/100) was from Biolegend. Secondary antibodies: Biomarkers were detected by a HRP-labeled polymeric anti-rabbit antibody (Dako, K4003), with the exception of CD91, which were visualized by a MACH2 rabbit AP-polymeric antibody (Biocare Medical, RALP525).

Flow Cytometry. Multiparameter staining for cell suspensions was performed as published previously. ${ }^{22}$ Briefly, tumor tissues collected during the vaccination and orthotopic efficacy studies were cut into small pieces, followed by digestion in collagenase type I ( 0.5 $\mathrm{mg} / \mathrm{mL}$, Worthington Biol Corporation) in a benchtop incubating shaker (MaxQ Digital 4450, Thermo Scientific) for $1 \mathrm{~h}$ at $37^{\circ} \mathrm{C}$. The digested tissues were meshed twice through a $70 \mu \mathrm{M}$ cell strainer, and the cell pellets suspended in $5 \mathrm{~mL}$ of Ack lysis buffer (Gibco) at $4{ }^{\circ} \mathrm{C}$ for $5 \mathrm{~min}$ to lyse red blood cells. After centrifugation at $1500 \mathrm{rpm}$ for 5 min, the single cell suspensions were washed twice with cold PBS twice and then resuspended in staining buffer (554656, BD Biosciences). To block nonspecific binding, cell suspensions were incubated with FcBlock (TruStain fcX anti-mouse CD16/32, clone 93, BioLegend) for $20 \mathrm{~min}$. Multiparameter staining was performed by utilizing different combinations of fluorophore-conjugated antibodies for $40 \mathrm{~min}$ at $4{ }^{\circ} \mathrm{C}$. Dead cells were excluded by 7 aminoactinomycin D (7AAD, Sigma) staining. Doublet cells were excluded based on their forward and side scatter characteristics. The following immune cell subpopulations were investigated, using multichannel gating: (i) $\mathrm{CD}^{+} \mathrm{T}$ cells $\left(\mathrm{CD} 45^{+} \mathrm{CD}^{+} \mathrm{CD}^{+} \mathrm{CD} 25^{+}\right)$, (ii) Tregs $\left(\mathrm{CD}_{4} 5^{+} \mathrm{CD}^{+} \mathrm{CD}^{+} \mathrm{FOXP3}^{+}\right)$, (iii) IFN- $\gamma^{+} \mathrm{T}$ cells $\left(\mathrm{CD} 45^{+} \mathrm{CD} 3^{+} \mathrm{CD} 8^{+} \mathrm{IFN}-\gamma^{+}\right)$, (iv) granzyme $\mathrm{B}^{+} \mathrm{T}$ cells $\left(\mathrm{CD} 45^{+} \mathrm{CD}^{+} \mathrm{CD}^{+}\right.$granzyme $\left.\mathrm{B}^{+}\right)$, (v) $\mathrm{CD}^{+} 1^{+}$DC-like cells $\left(\mathrm{CD} 45^{+} \mathrm{CD} 11 \mathrm{~b}^{+} \mathrm{CD} 11 \mathrm{c}^{+} \mathrm{CD} 91^{+}\right)$, (vi) $\mathrm{CD} 80^{+} / \mathrm{CD} 86^{+} \mathrm{DCs}$ $\left(\mathrm{CD} 45^{+} \mathrm{CD} 11 \mathrm{c}^{+} \mathrm{CD} 80^{+} \mathrm{CD} 86^{+}\right.$), and (vii) $\mathrm{CD} 103^{+} \mathrm{DCs}$ $\left(\mathrm{CD}_{4} 5^{+} \mathrm{CD} 11 \mathrm{~b}^{+} \mathrm{CD} 11 \mathrm{c}^{+} \mathrm{CD} 103^{+}\right)$. Anti-mouse antibodies sources are as follows: CD45-V450 (\#560501, 1/100), CD45-APC-Cy7 (\#557659, 1/100), CD4-Alexa Fluor 488 (\#557667, 1/100), FOXP3PE (\#563101, 1/100), CD $8 \alpha$-PE (\#561095, 1/100), CD11b-PE (553311, 1/100), and CD11c-V450 (560521,1/100) were from BD Biosciences; CD103-Alexa Fluor 647 (\#121410, 1/250) and IFN- $\gamma$ APC (505810, 1/100) were from BioLegend. LRP1 (CD91)-Alexa Fluor 647 (ab195568, 1/250) were from Abcam. CD3-APCeFluor780 (\#47-0032-82, 1/100), CD25-APC (\#17-0251-82, $1 /$ $100)$ and granzyme B-eFluor 660 (50-8898-82, 1/100) were from eBiosciences. For intracellular staining of FOXP3, IFN- $\gamma$, and granzyme B, cells were fixed and permeabilized using a Staining Buffer Set (00-5523-00, eBioscience) followed by PBS washing prior to conducting flow cytometry in a LSRII (BD Biosciences). The data were plotted as a change in the normalized ratio in the experimental versus the control sample by FlowJo software (Tree Star).
Statistical Analysis. Differences among groups were estimated by the analysis of variance (ANOVA); Kaplan-Meier survival curves were compared using the Log-rank Mantel-Cox test (version 23, SPSS). Results were presented as mean \pm standard deviation (SD), representing at least three independent experiments. Statistical significance was set at $* p<0.05 ; * *<0.01 ;{ }^{*} p<0.001$, as indicated in the figure legends.

\section{ASSOCIATED CONTENT}

\section{S Supporting Information}

The Supporting Information is available free of charge on the ACS Publications website at DOI: 10.1021/acsnano.8b05189.

Additional figures, table, and results as described in the text (PDF)

\section{AUTHOR INFORMATION}

\section{Corresponding Authors}

*Phone: 310.825.0217. E-mail: hmeng@mednet.ucla.edu. *Phone: 310.825.6620. E-mail: anel@mednet.ucla.edu. ORCID $\odot$

Jianqin Lu: 0000-0002-5877-619X

Xiangsheng Liu: 0000-0002-5719-2838

Wen Jiang: 0000-0003-2083-2069

Huan Meng: 0000-0001-8844-3938

Andre E. Nel: 0000-0002-5232-4686

\section{Notes}

The authors declare the following competing financial interest(s): Andre E. Nel and Huan Meng are co-founders and equity holders in Westwood Biosciences Inc. The remaining authors declare no conflict of interest.

\section{ACKNOWLEDGMENTS}

Research reported in this publication was supported by the National Cancer Institute of the National Institutes of Health under Award Number, U01CA198846. J.L. is a recipient of the UCLA Tumor Immunology Training Grant (USHHS Ruth L. Kirschstein Institutional National Research Service Award No. T32 CA009120). The content is solely the responsibility of the authors and does not necessarily represent the official views of the National Institutes of Health. We thank the Translational Pathology Core Laboratory (TPCL) at UCLA Jonsson Comprehensive Cancer Center for IHC staining, the Electron Imaging Center for Nanomachines the use of EM instruments at, the Molecular Instrumentation Center for NMRs and Mass Spectrometry, the CNSI Advanced Light Microscopy/Spectroscopy Shared Facility for confocal fluorescent microscopy.

\section{REFERENCES}

(1) Edwards, B. K.; Ward, E.; Kohler, B. A.; Eheman, C.; Zauber, A. G.; Anderson, R. N.; Jemal, A.; Schymura, M. J.; Lansdorp-Vogelaar, I.; Seeff, L. C.; van Ballegooijen, M. C.; Goede, S. L.; Ries, L. A. G. Annual Report to the Nation on the Status of Cancer, 1975-2006, Featuring Colorectal Cancer Trends and Impact of Interventions (risk factors, screening, and treatment) to Reduce Future Rates. Cancer 2010, 116, 544-573.

(2) Rashid, O. M.; Takabe, K. Does Removal of the Primary Tumor in Metastatic Breast Cancer Improve Survival? J. Womens Health 2014, 23, 184-188.

(3) Pardoll, D. M. The Blockade of Immune Checkpoints in Cancer Immunotherapy. Nat. Rev. Cancer 2012, 12, 252-264.

(4) Sharma, P.; Allison, J. P. The Future of Immune Checkpoint Therapy. Science 2015, 348, 56-61. 
(5) Sharma, P.; Wagner, K.; Wolchok, J. D.; Allison, J. P. Novel Cancer Immunotherapy Agents with Survival Benefit: Recent Successes and Next steps. Nat. Rev. Cancer 2011, 11, 805-812.

(6) Vonderheide, R. H.; Domchek, S. M.; Clark, A. S. Immunotherapy for Breast Cancer: What Are We Missing? Clin. Cancer Res. 2017, 23, 2640-2646.

(7) Nagarsheth, N.; Wicha, M. S.; Zou, W. Chemokines in the Cancer Microenvironment and Their Relevance in Cancer Immunotherapy. Nat. Rev. Immunol. 2017, 17, 559-572.

(8) Stephens, P. J.; Tarpey, P. S.; Davies, H.; Van Loo, P.; Greenman, C.; Wedge, D. C.; Nik-Zainal, S.; Martin, S.; Varela, I.; Bignell, G. R.; Yates, L. R.; Papaemmanuil, E.; Beare, D.; Butler, A.; Cheverton, A.; Gamble, J.; Hinton, J.; Jia, M.; Jayakumar, A.; Jones, D.; et al. The Landscape of Cancer Genes and Mutational Processes in Breast Cancer. Nature 2012, 486, 400-404.

(9) Zhang, X.; Kim, S.; Hundal, J.; Herndon, J. M.; Li, S.; Petti, A. A.; Soysal, S. D.; Li, L.; McLellan, M. D.; Hoog, J.; Primeau, T.; Myers, N.; Vickery, T. L.; Sturmoski, M.; Hagemann, I. S.; Miller, C. A.; Ellis, M. J.; Mardis, E. R.; Hansen, T.; Fleming, T. P.; et al. Breast Cancer Neoantigens Can Induce CD8(+) T-Cell Responses and Antitumor Immunity. Cancer Immunol. Res. 2017, 5, 516-523.

(10) Colli, L. M.; Machiela, M. J.; Myers, T. A.; Jessop, L.; Yu, K.; Chanock, S. J. Burden of Nonsynonymous Mutations Among TCGA Cancers and Candidate Immune Checkpoint Inhibitor Responses. Cancer Res. 2016, 76, 3767-3772.

(11) Zappasodi, R.; Merghoub, T.; Wolchok, J. D. Emerging Concepts for Immune Checkpoint Blockade-Based Combination Therapies. Cancer Cell 2018, 33, 581-598.

(12) Dushyanthen, S.; Beavis, P. A.; Savas, P.; Teo, Z. L.; Zhou, C.; Mansour, M.; Darcy, P. K.; Loi, S. Relevance of Tumor-Infiltrating Lymphocytes in Breast Cancer. BMC Med. 2015, 13, 202.

(13) Nagarajan, D.; McArdle, S. E. B. Immune Landscape of Breast Cancers. Biomedicines 2018, 6, 20.

(14) Denkert, C.; Loibl, S.; Noske, A.; Roller, M.; Muller, B. M.; Komor, M.; Budczies, J.; Darb-Esfahani, S.; Kronenwett, R.; Hanusch, C.; von Törne, C.; Weichert, W.; Engels, K.; Solbach, C.; Schrader, I.; Dietel, M.; von Minckwitz, G. Tumor-Associated Lymphocytes as an Independent Predictor of Response to Neoadjuvant Chemotherapy in Breast Cancer. J. Clin. Oncol. 2010, 28, 105-113.

(15) Kroemer, G.; Senovilla, L.; Galluzzi, L.; Andre, F.; Zitvogel, L. Natural and Therapy-Induced Immunosurveillance in Breast Cancer. Nat. Med. 2015, 21, 1128-1138.

(16) Loi, S.; Sirtaine, N.; Piette, F.; Salgado, R.; Viale, G.; Van Eenoo, F.; Rouas, G.; Francis, P.; Crown, J. P.; Hitre, E.; de Azambuja, E.; Quinaux, E.; Di Leo, A.; Michiels, S.; Piccart, M. J.; Sotiriou, C. Prognostic and Predictive Value of Tumor-infiltrating Lymphocytes in a Phase III Randomized Adjuvant Breast Cancer Trial in Node-positive Breast Cancer Comparing the Addition of Docetaxel to Doxorubicin with Doxorubicin-Based Chemotherapy: BIG 02-98. J. Clin. Oncol. 2013, 31, 860-867.

(17) Ladoire, S.; Arnould, L.; Apetoh, L.; Coudert, B.; Martin, F.; Chauffert, B.; Fumoleau, P.; Ghiringhelli, F. Pathologic Complete Response to Neoadjuvant Chemotherapy of Breast Carcinoma Is Associated with the Disappearance of Tumor-infiltrating Foxp3+ Regulatory T Cells. Clin. Cancer Res. 2008, 14, 2413-2420.

(18) Senovilla, L.; Vitale, I.; Martins, I.; Tailler, M.; Pailleret, C.; Michaud, M.; Galluzzi, L.; Adjemian, S.; Kepp, O.; Niso-Santano, M.; Shen, S.; Mariño, G.; Criollo, A.; Boilève, A.; Job, B.; Ladoire, S.; Ghiringhelli, F.; Sistigu, A.; Yamazaki, T.; Rello-Varona, S.; et al. An Immunosurveillance Mechanism Controls Cancer Cell Ploidy. Science 2012, 337, 1678-1684.

(19) Spranger, S.; Spaapen, R. M.; Zha, Y.; Williams, J.; Meng, Y.; Ha, T. T.; Gajewski, T. F. Up-Regulation of PD-L1, IDO, and T(regs) in the Melanoma Tumor Microenvironment Is Driven by CD8(+) T cells. Sci. Transl. Med. 2013, 5, 200ra116.

(20) Rugo, H.; Delord, J.; Im, S.; Ott, P.; Piha-Paul, S.; Bedard, P.; Sachdev, J.; Le Tourneau, C.; Van Brummelen, E.; Varga, A. Abstract S5-07: Preliminary Efficacy and Safety of Pembrolizumab (MK3475) in Patients with PD-L1-positive, Estrogen Receptor-Positive
(ER+)/HER2-Negative Advanced Breast Cancer Enrolled in KEYNOTE-028. Cancer Res. 2016, 76, S5-07.

(21) Kroemer, G.; Galluzzi, L.; Kepp, O.; Zitvogel, L. Immunogenic Cell Death in Cancer Therapy. Annu. Rev. Immunol. 2013, 31, 51-72.

(22) Lu, J.; Liu, X.; Liao, Y. P.; Salazar, F.; Sun, B.; Jiang, W.; Chang, C. H.; Jiang, J.; Wang, X.; Wu, A. M.; Meng, H.; Nel, A. E. NanoEnabled Pancreas Cancer Immunotherapy Using Immunogenic Cell Death and Reversing Immunosuppression. Nat. Commun. 2017, 8, 1811.

(23) Pol, J.; Vacchelli, E.; Aranda, F.; Castoldi, F.; Eggermont, A.; Cremer, I.; Sautes-Fridman, C.; Fucikova, J.; Galon, J.; Spisek, R.; Tartour, E.; Zitvogel, L.; Kroemer, G.; Galluzzi, L. Trial Watch: Immunogenic Cell Death Inducers for Anticancer Chemotherapy. Oncoimmunology 2015, 4, e1008866.

(24) Basu, S.; Binder, R. J.; Ramalingam, T.; Srivastava, P. K. CD91 Is a Common Receptor for Heat Shock Proteins Gp96, Hsp90, Hsp70, and Calreticulin. Immunity 2001, 14, 303-313.

(25) Gardai, S. J.; Xiao, Y. Q.; Dickinson, M.; Nick, J. A.; Voelker, D. R.; Greene, K. E.; Henson, P. M. By Binding SIRPalpha or Calreticulin/CD91, Lung Collectins Act as Dual Function Surveillance Molecules to Suppress or Enhance Inflammation. Cell 2003, $115,13-23$.

(26) Obeid, M.; Tesniere, A.; Ghiringhelli, F.; Fimia, G. M.; Apetoh, L.; Perfettini, J. L.; Castedo, M.; Mignot, G.; Panaretakis, T.; Casares, N.; Métivier, D.; Larochette, N.; van Endert, P.; Ciccosanti, F.; Piacentini, M.; Zitvogel, L.; Kroemer, G. Calreticulin Exposure Dictates the Immunogenicity of Cancer Cell Death. Nat. Med. 2007, $13,54-61$.

(27) Zitvogel, L.; Kepp, O.; Senovilla, L.; Menger, L.; Chaput, N.; Kroemer, G. Immunogenic Tumor Cell Death for Optimal Anticancer Therapy: the Calreticulin Exposure Pathway. Clin. Cancer Res. 2010, 16, 3100-3104.

(28) Apetoh, L.; Ghiringhelli, F.; Tesniere, A.; Obeid, M.; Ortiz, C.; Criollo, A.; Mignot, G.; Maiuri, M. C.; Ullrich, E.; Saulnier, P.; Yang, H.; Amigorena, S.; Ryffel, B.; Barrat, F. J.; Saftig, P.; Levi, F.; Lidereau, R.; Nogues, C.; Mira, J. P.; Chompret, A.; et al. Toll-like Receptor 4Dependent Contribution of the Immune System to Anticancer Chemotherapy and Radiotherapy. Nat. Med. 2007, 13, 1050-1059.

(29) Casares, N.; Pequignot, M. O.; Tesniere, A.; Ghiringhelli, F.; Roux, S.; Chaput, N.; Schmitt, E.; Hamai, A.; Hervas-Stubbs, S.; Obeid, M.; Coutant, F.; Métivier, D.; Pichard, E.; Aucouturier, P.; Pierron, G.; Garrido, C.; Zitvogel, L.; Kroemer, G. Caspasedependent Immunogenicity of Doxorubicin-Induced Tumor Cell Death. J. Exp. Med. 2005, 202, 1691-1701.

(30) Fucikova, J.; Kralikova, P.; Fialova, A.; Brtnicky, T.; Rob, L.; Bartunkova, J.; Spisek, R. Human Tumor Cells Killed by Anthracyclines Induce a Tumor-specific Immune Response. Cancer Res. 2011, 71, 4821-4833.

(31) Michaud, M.; Martins, I.; Sukkurwala, A. Q.; Adjemian, S.; Ma, Y.; Pellegatti, P.; Shen, S.; Kepp, O.; Scoazec, M.; Mignot, G.; RelloVarona, S.; Tailler, M.; Menger, L.; Vacchelli, E.; Galluzzi, L.; Ghiringhelli, F.; di Virgilio, F.; Zitvogel, L.; Kroemer, G. AutophagyDependent Anticancer Immune Responses Induced by Chemotherapeutic Agents in Mice. Science 2011, 334, 1573-1577.

(32) Zou, W. Immunosuppressive Networks in the Tumour Environment and Their Therapeutic Relevance. Nat. Rev. Cancer 2005, 5, 263-274.

(33) Soliman, H.; Rawal, B.; Fulp, J.; Lee, J. H.; Lopez, A.; Bui, M. M.; Khalil, F.; Antonia, S.; Yfantis, H. G.; Lee, D. H.; Dorsey, T. H.; Ambs, S. Analysis of Indoleamine 2-3 Dioxygenase (IDO1) Expression in Breast Cancer Tissue by Immunohistochemistry. Cancer Immunol. Immunother. 2013, 62, 829-837.

(34) Telli, M. L.; Carlson, R. W. First-Line Chemotherapy for Metastatic Breast Cancer. Clin. Breast Cancer 2009, 9, S66-S72.

(35) Lu, J.; Zhao, W.; Huang, Y.; Liu, H.; Marquez, R.; Gibbs, R. B.; Li, J.; Venkataramanan, R.; Xu, L.; Li, S.; Li, S. Targeted Delivery of Doxorubicin by Folic Acid-decorated Dual Functional Nanocarrier. Mol. Pharmaceutics 2014, 11, 4164-4178. 
(36) Lu, J.; Zhao, W.; Liu, H.; Marquez, R.; Huang, Y.; Zhang, Y.; Li, J.; Xie, W.; Venkataramanan, R.; Xu, L.; Li, S. An Improved D-AlphaTocopherol-Based Nanocarrier for Targeted Delivery of Doxorubicin with Reversal of Multidrug Resistance. J. Controlled Release 2014, 196, 272-286.

(37) Zhang, X.; Huang, Y.; Zhao, W.; Liu, H.; Marquez, R.; Lu, J.; Zhang, P.; Zhang, Y.; Li, J.; Gao, X.; Venkataramanan, R.; Xu, L.; Li, S. Targeted Delivery of Anticancer Agents via a Dual Function Nanocarrier with an Interfacial Drug-Interactive Motif. Biomacromolecules 2014, 15, 4326-4335.

(38) Duggan, S. T.; Keating, G. M. Pegylated Liposomal Doxorubicin: a Review of Its Use in Metastatic Breast Cancer, Ovarian Cancer, Multiple Myeloma and AIDS-related Kaposi's Sarcoma. Drugs 2011, 71, 2531-2558.

(39) Gabizon, A.; Shmeeda, H.; Barenholz, Y. Pharmacokinetics of Pegylated Liposomal Doxorubicin. Clin. Pharmacokinet. 2003, 42, 419-436.

(40) Kohli, A. G.; Kivimae, S.; Tiffany, M. R.; Szoka, F. C. Improving the Distribution of Doxil ${ }^{\circledR}$ in the Tumor Matrix by Depletion of Tumor Hyaluronan. J. Controlled Release 2014, 191, $105-114$.

(41) Platten, M.; von Knebel Doeberitz, N.; Oezen, I.; Wick, W.; Ochs, K. Cancer Immunotherapy by Targeting IDO1/TDO and Their Downstream Effectors. Front. Immunol. 2015, 5, 673.

(42) Litzenburger, U. M.; Opitz, C. A.; Sahm, F.; Rauschenbach, K. J.; Trump, S.; Winter, M.; Ott, M.; Ochs, K.; Lutz, C.; Liu, X.; Anastasov, N.; Lehmann, I.; Höfer, T.; von Deimling, A.; Wick, W.; Platten, M. Constitutive IDO Expression in Human Cancer Is Sustained by an Autocrine Signaling Loop Involving IL-6, STAT3 and the AHR. Oncotarget 2014, 5, 1038-1051.

(43) Prendergast, G. C.; Malachowski, W. P.; DuHadaway, J. B.; Muller, A. J. Discovery of IDO1 Inhibitors: From Bench to Bedside. Cancer Res. 2017, 77, 6795-6811.

(44) Pfirschke, C.; Engblom, C.; Rickelt, S.; Cortez-Retamozo, V.; Garris, C.; Pucci, F.; Yamazaki, T.; Poirier-Colame, V.; Newton, A.; Redouane, Y.; Lin, Y. J.; Wojtkiewicz, G.; Iwamoto, Y.; MinoKenudson, M.; Huynh, T. G.; Hynes, R. O.; Freeman, G. J.; Kroemer, G.; Zitvogel, L.; Weissleder, R.; et al. Immunogenic Chemotherapy Sensitizes Tumors to Checkpoint Blockade Therapy. Immunity 2016, 44, 343-354.

(45) Kepp, O.; Senovilla, L.; Vitale, I.; Vacchelli, E.; Adjemian, S.; Agostinis, P.; Apetoh, L.; Aranda, F.; Barnaba, V.; Bloy, N.; Bracci, L.; Breckpot, K.; Brough, D.; Buqué, A.; Castro, M. G.; Cirone, M.; Colombo, M. I.; Cremer, I.; Demaria, S.; Dini, L.; et al. Consensus Guidelines for the Detection of Immunogenic Cell Death. Oncoimmunology 2014, 3, e955691.

(46) Wen, H.; Jung, H.; Li, X. Drug Delivery Approaches in Addressing Clinical Pharmacology-Related Issues: Opportunities and Challenges. AAPS J. 2015, 17, 1327-1340.

(47) Lengyel, J. S.; Milne, J. L. S.; Subramaniam, S. Electron Tomography in Nanoparticle Imaging and Analysis. Nanomedicine (London, U. K.) 2008, 3, 125.

(48) Rashid, O. M.; Nagahashi, M.; Ramachandran, S.; Dumur, C.; Schaum, J.; Yamada, A.; Terracina, K. P.; Milstien, S.; Spiegel, S.; Takabe, K. An Improved Syngeneic Orthotopic Murine Model of Human Breast Cancer Progression. Breast Cancer Res. Treat. 2014, $147,501-512$.

(49) Drummond, D. C.; Noble, C. O.; Guo, Z.; Hong, K.; Park, J. W.; Kirpotin, D. B. Development of a Highly Active Nanoliposomal Irinotecan Using A Novel Intraliposomal Stabilization Strategy. Cancer Res. 2006, 66, 3271-3277.

(50) Rose, P. G. Pegylated Liposomal Doxorubicin: Optimizing the Dosing Schedule in Ovarian Cancer. Oncologist 2005, 10, 205-214.

(51) Leventakos, K.; Mansfield, A. S. Reflections on Immune Checkpoint Inhibition in Non-Small Cell Lung Cancer. Transl. Lung Cancer Res. 2014, 3, 411-413.

(52) Vanpouille-Box, C.; Lhuillier, C.; Bezu, L.; Aranda, F.; Yamazaki, T.; Kepp, O.; Fucikova, J.; Spisek, R.; Demaria, S.; Formenti, S. C.; Zitvogel, L.; Kroemer, G.; Galluzzi, L. Trial Watch:
Immune Checkpoint Blockers for Cancer Therapy. Oncoimmunology 2017, 6, e1373237.

(53) Denkert, C.; von Minckwitz, G.; Brase, J. C.; Sinn, B. V.; Gade, S.; Kronenwett, R.; Pfitzner, B. M.; Salat, C.; Loi, S.; Schmitt, W. D.; Schem, C.; Fisch, K.; Darb-Esfahani, S.; Mehta, K.; Sotiriou, C.; Wienert, S.; Klare, P.; André, F.; Klauschen, F.; Blohmer, J. U.; et al. Tumor-Infiltrating Lymphocytes and Response to Neoadjuvant Chemotherapy with or Without Carboplatin in Human Epidermal Growth Factor Receptor 2-Positive and Triple-Negative Primary Breast Cancers. J. Clin. Oncol. 2015, 33, 983-991.

(54) Dehal, A.; Graff-Baker, A. N.; Vuong, B.; Fischer, T.; Klempner, S. J.; Chang, S. C.; Grunkemeier, G. L.; Bilchik, A. J.; Goldfarb, M. Neoadjuvant Chemotherapy Improves Survival in Patients with Clinical T4b Colon Cancer. J. Gastrointest. Surg.: official journal of the Society for Surgery of the Alimentary Tract 2018, 22, 242-249.

(55) Tsai, C. C.; Huang, C. H.; Huang, C. N.; Wu, W. J.; Yeh, H. C.; Li, W. M.; Li, C. C.; Lee, M. H. Neoadjuvant Chemotherapy Improves Survival Rate in Advanced Urothelial Carcinoma. Kaohsiung J. Med. Sci. 2013, 29, 200-205.

(56) Tesniere, A.; Schlemmer, F.; Boige, V.; Kepp, O.; Martins, I.; Ghiringhelli, F.; Aymeric, L.; Michaud, M.; Apetoh, L.; Barault, L.; Mendiboure, J.; Pignon, J. P.; Jooste, V.; van Endert, P.; Ducreux, M.; Zitvogel, L.; Piard, F.; Kroemer, G. Immunogenic Death of Colon Cancer Cells Treated with Oxaliplatin. Oncogene 2010, 29, 482-491.

(57) Lotze, M. T.; Tracey, K. J. High-Mobility Group Box 1 Protein (HMGB1): Nuclear Weapon in the Immune Arsenal. Nat. Rev. Immunol. 2005, 5, 331-342.

(58) Martins, I.; Wang, Y.; Michaud, M.; Ma, Y.; Sukkurwala, A. Q.; Shen, S.; Kepp, O.; Metivier, D.; Galluzzi, L.; Perfettini, J. L.; Zitvogel, L.; Kroemer, G. Molecular Mechanisms of ATP Secretion During Immunogenic Cell Death. Cell Death Differ. 2014, 21, 79-91.

(59) Wang, Y.; Martins, I.; Ma, Y.; Kepp, O.; Galluzzi, L.; Kroemer, G. Autophagy-Dependent ATP Release from Dying Cells via Lysosomal Exocytosis. Autophagy 2013, 9, 1624-1625.

(60) Gombault, A.; Baron, L.; Couillin, I. ATP Release and Purinergic Signaling in NLRP3 Inflammasome Activation. Front. Immunol. 2013, 3, 414.

(61) Latz, E.; Xiao, T. S.; Stutz, A. Activation and Regulation of the Inflammasomes. Nat. Rev. Immunol. 2013, 13, 397-411.

(62) Piccini, A.; Carta, S.; Tassi, S.; Lasiglie, D.; Fossati, G.; Rubartelli, A. ATP Is Released by Monocytes Stimulated with Pathogen-sensing Receptor Ligands and Induces IL-1beta and IL-18 Secretion in an Autocrine Way. Proc. Natl. Acad. Sci. U. S. A. 2008, $105,8067-8072$.

(63) Riteau, N.; Baron, L.; Villeret, B.; Guillou, N.; Savigny, F.; Ryffel, B.; Rassendren, F.; Le Bert, M.; Gombault, A.; Couillin, I. ATP Release and Purinergic Signaling: a Common Pathway for ParticleMediated Inflammasome Activation. Cell Death Dis. 2012, 3, e403.

(64) He, C.; Duan, X.; Guo, N.; Chan, C.; Poon, C.; Weichselbaum, R. R.; Lin, W. Core-Shell Nanoscale Coordination Polymers Combine Chemotherapy and Photodynamic Therapy to Potentiate Checkpoint Blockade Cancer Immunotherapy. Nat. Commun. 2016, 7, 12499.

(65) Adkins, I.; Fucikova, J.; Garg, A. D.; Agostinis, P.; Spisek, R. Physical Modalities Inducing Immunogenic Tumor Cell Death for Cancer Immunotherapy. Oncoimmunology 2014, 3, e968434.

(66) Gabizon, A.; Goren, D.; Horowitz, A. T.; Tzemach, D.; Lossos, A.; Siegal, T. Long-Circulating Liposomes for Drug Delivery in Cancer Therapy: a Review of Biodistribution Studies in TumorBearing Animals. Adv. Drug Delivery Rev. 1997, 24, 337-344.

(67) Gaillard, P. J.; Appeldoorn, C. C.; Dorland, R.; van Kregten, J.; Manca, F.; Vugts, D. J.; Windhorst, B.; van Dongen, G. A.; de Vries, H. E.; Maussang, D.; van Tellingen, O. Pharmacokinetics, Brain Delivery, and Efficacy in Brain Tumor-Bearing Mice of Glutathione Pegylated Liposomal Doxorubicin (2B3-101). PLoS One 2014, 9, e82331.

(68) Vail, D. M.; Amantea, M. A.; Colbern, G. T.; Martin, F. J.; Hilger, R. A.; Working, P. K. Pegylated Liposomal Doxorubicin: Proof of Principle Using Preclinical Animal Models and Pharmacokinetic Studies. Semin. Oncol. 2004, 31, 16-35. 
(69) Sun, J. J.; Chen, Y. C.; Huang, Y. X.; Zhao, W. C.; Liu, Y. H.; Venkataramanan, R.; Lu, B. F.; Li, S. Programmable Co-delivery of the Immune Checkpoint Inhibitor NLG919 and Chemotherapeutic Doxorubicin via a Redox-Responsive Immunostimulatory Polymeric Prodrug Carrier. Acta Pharmacol. Sin. 2017, 38, 823-834.

(70) National Library of Medicine (US). Identifier NCT02048709, Indoleamine 2,3-Dioxygenase (IDO) Inhibitor in Advanced Solid Tumors. Jan 29, 2014-Feb 6, 2017. Available from https:// clinicaltrials.gov/ct2/show/NCT02048709.

(71) National Library of Medicine (US). Identifier NCT02471846, A Study of GDC-0919 and Atezolizumab Combination Treatment in Participants with Locally Advanced or Metastatic Solid Tumors. June 15, 2015-July 30, 2018. Available from https://clinicaltrials.gov/ct2/ show/NCT02471846.

(72) Beatty, G. L.; O’Dwyer, P. J.; Clark, J.; Shi, J. G.; Bowman, K. J.; Scherle, P. A.; Newton, R. C.; Schaub, R.; Maleski, J.; Leopold, L.; Gajewski, T. F. First-in-Human Phase I Study of the Oral Inhibitor of Indoleamine 2,3-Dioxygenase-1 Epacadostat (INCB024360) in Patients with Advanced Solid Malignancies. Clin. Cancer Res. 2017, 23, 3269-3276.

(73) Dhiman, V.; Giri, K. K.; S, S. P.; Zainuddin, M.; Rajagopal, S.; Mullangi, R. Determination of Epacadostat, a Novel IDO1 Inhibitor in Mouse Plasma by LC-MS/MS and Its Application to a Pharmacokinetic Study in Mice. Biomed. Chromatogr. 2017, 31, e3794.

(74) Yue, E. W.; Sparks, R.; Polam, P.; Modi, D.; Douty, B.; Wayland, B.; Glass, B.; Takvorian, A.; Glenn, J.; Zhu, W.; Bower, M.; Liu, X.; Leffet, L.; Wang, Q.; Bowman, K. J.; Hansbury, M. J.; Wei, M.; Li, Y.; Wynn, R.; Burn, T. C.; et al. INCB24360 (Epacadostat), a Highly Potent and Selective Indoleamine-2,3-Dioxygenase 1 (IDO1) Inhibitor for Immuno-oncology. ACS Med. Chem. Lett. 2017, 8, 486491.

(75) Dang, T. O.; Ogunniyi, A.; Barbee, M. S.; Drilon, A. Pembrolizumab for the Treatment of PD-L1 Positive Advanced or Metastatic Non-Small Cell Lung Cancer. Expert Rev. Anticancer Ther. 2016, 16, 13-20.

(76) Emens, L. A.; Ascierto, P. A.; Darcy, P. K.; Demaria, S.; Eggermont, A. M. M.; Redmond, W. L.; Seliger, B.; Marincola, F. M. Cancer Immunotherapy: Opportunities and Challenges in the Rapidly Evolving Clinical Landscape. Eur. J. Cancer 2017, 81, 116-129.

(77) Harris, S. J.; Brown, J.; Lopez, J.; Yap, T. A.; et al. ImmunoOncology Combinations: Raising the Tail of the Survival Curve. Cancer Biol. Med. 2016, 13, 171-193.

(78) Jacquelot, N.; Roberti, M. P.; Enot, D. P.; Rusakiewicz, S.; Ternes, N.; Jegou, S.; Woods, D. M.; Sodre, A. L.; Hansen, M.; Meirow, Y.; Sade-Feldman, M.; Burra, A.; Kwek, S. S.; Flament, C.; Messaoudene, M.; Duong, C. P. M.; Chen, L.; Kwon, B. S.; Anderson, A. C.; Kuchroo, V. K.; et al. Predictors of Responses to Immune Checkpoint Blockade in Advanced Melanoma. Nat. Commun. 2017, 8 , 592.

(79) Johnson, D. B.; Rioth, M. J.; Horn, L. Immune Checkpoint Inhibitors in NSCLC. Curr. Treat. Options Oncol 2014, 15, 658-669.

(80) Ferris, R. L.; Lenz, H. J.; Trotta, A. M.; Garcia-Foncillas, J.; Schulten, J.; Audhuy, F.; Merlano, M.; Milano, G. Rationale for Combination of Therapeutic Antibodies Targeting Tumor Cells and Immune Checkpoint Receptors: Harnessing Innate and Adaptive Immunity Through LgG1 Isotype Immune Effector Stimulation. Cancer Treat. Rev. 2018, 63, 48-60.

(81) Sharma, P.; Hu-Lieskovan, S.; Wargo, J. A.; Ribas, A. Primary, Adaptive, and Acquired Resistance to Cancer Immunotherapy. Cell 2017, 168, 707-723.

(82) Wargo, J. A.; Reddy, S. M.; Reuben, A.; Sharma, P. Monitoring Immune Responses in the Tumor Microenvironment. Curr. Opin. Immunol. 2016, 41, 23-31.

(83) Zito Marino, F.; Ascierto, P. A.; Rossi, G.; Staibano, S.; Montella, M.; Russo, D.; Alfano, R.; Morabito, A.; Botti, G.; Franco, R. Are Tumor-Infiltrating Lymphocytes Protagonists or Background Actors in Patient Selection for Cancer Immunotherapy? Expert Opin. Biol. Ther. 2017, 17, 735-746.
(84) Dunn, G. P.; Bruce, A. T.; Ikeda, H.; Old, L. J.; Schreiber, R. D. Cancer Immunoediting: from Immunosurveillance to Tumor Escape. Nat. Immunol. 2002, 3, 991-998.

(85) Gubin, M. M.; Zhang, X.; Schuster, H.; Caron, E.; Ward, J. P.; Noguchi, T.; Ivanova, Y.; Hundal, J.; Arthur, C. D.; Krebber, W. J.; Mulder, G. E.; Toebes, M.; Vesely, M. D.; Lam, S. S.; Korman, A. J.; Allison, J. P.; Freeman, G. J.; Sharpe, A. H.; Pearce, E. L.; Schumacher, T. N.; et al. Checkpoint Blockade Cancer Immunotherapy Targets Tumour-Specific Mutant Antigens. Nature 2014, 515, $577-581$

(86) Rizvi, N. A.; Hellmann, M. D.; Snyder, A.; Kvistborg, P.; Makarov, V.; Havel, J. J.; Lee, W.; Yuan, J.; Wong, P.; Ho, T. S.; Miller, M. L.; Rekhtman, N.; Moreira, A. L.; Ibrahim, F.; Bruggeman, C.; Gasmi, B.; Zappasodi, R.; Maeda, Y.; Sander, C.; Garon, E. B.; et al. Cancer Immunology. Mutational Landscape Determines Sensitivity to PD-1 Blockade in Non-Small Cell Lung Cancer. Science 2015, 348, 124-128.

(87) Comber, J. D.; Philip, R. MHC Class I Antigen Presentation and Implications for Developing a New Generation of Therapeutic Vaccines. Ther. Adv. Vaccines 2014, 2, 77-89.

(88) Palucka, K.; Banchereau, J. Dendritic-Cell-Based Therapeutic Cancer Vaccines. Immunity 2013, 39, 38-48.

(89) McGranahan, N.; Furness, A. J.; Rosenthal, R.; Ramskov, S.; Lyngaa, R.; Saini, S. K.; Jamal-Hanjani, M.; Wilson, G. A.; Birkbak, N. J.; Hiley, C. T.; Watkins, T. B.; Shafi, S.; Murugaesu, N.; Mitter, R.; Akarca, A. U.; Linares, J.; Marafioti, T.; Henry, J. Y.; Van Allen, E. M.; Miao, D.; et al. Clonal Neoantigens Elicit T Cell Immunoreactivity and Sensitivity to Immune Checkpoint Blockade. Science 2016, 351, $1463-1469$.

(90) Pearce, E. L.; Walsh, M. C.; Cejas, P. J.; Harms, G. M.; Shen, H.; Wang, L. S.; Jones, R. G.; Choi, Y. Enhancing CD8 T-Cell Memory by Modulating Fatty Acid Metabolism. Nature 2009, 460, 103-107.

(91) Snyder, A.; Makarov, V.; Merghoub, T.; Yuan, J.; Zaretsky, J. M.; Desrichard, A.; Walsh, L. A.; Postow, M. A.; Wong, P.; Ho, T. S.; Hollmann, T. J.; Bruggeman, C.; Kannan, K.; Li, Y.; Elipenahli, C.; Liu, C.; Harbison, C. T.; Wang, L.; Ribas, A.; Wolchok, J. D.; et al. Genetic Basis for Clinical Response to CTLA-4 Blockade in Melanoma. N. Engl. J. Med. 2014, 371, 2189-2199.

(92) Walunas, T. L.; Lenschow, D. J.; Bakker, C. Y.; Linsley, P. S.; Freeman, G. J.; Green, J. M.; Thompson, C. B.; Bluestone, J. A. CTLA-4 Can Function as a Negative Regulator of T Cell Activation. Immunity 1994, 1, 405-413.

(93) Nishimura, H.; Nose, M.; Hiai, H.; Minato, N.; Honjo, T. Development of Lupus-like Autoimmune Diseases by Disruption of the PD-1 Gene Encoding an ITIM Motif-Carrying Immunoreceptor. Immunity 1999, 11, 141-151.

(94) Nishimura, H.; Okazaki, T.; Tanaka, Y.; Nakatani, K.; Hara, M.; Matsumori, A.; Sasayama, S.; Mizoguchi, A.; Hiai, H.; Minato, N.; Honjo, T. Autoimmune Dilated Cardiomyopathy in PD-1 ReceptorDeficient Mice. Science 2001, 291, 319-322.

(95) Salomon, B.; Bluestone, J. A. Complexities of CD28/B7: CTLA-4 Costimulatory Pathways in Autoimmunity and Transplantation. Annu. Rev. Immunol. 2001, 19, 225-252.

(96) Wang, J.; Yoshida, T.; Nakaki, F.; Hiai, H.; Okazaki, T.; Honjo, T. Establishment of NOD-Pdcd1-/- Mice as an Efficient Animal Model of Type I Diabetes. Proc. Natl. Acad. Sci. U. S. A. 2005, 102, 11823-11828.

(97) Green, D. R.; Ferguson, T.; Zitvogel, L.; Kroemer, G. Immunogenic and Tolerogenic Cell Death. Nat. Rev. Immunol. 2009, 9, 353-363.

(98) Nagata, S.; Tanaka, M. Programmed Cell Death and the Immune System. Nat. Rev. Immunol. 2017, 17, 333-340.

(99) Kaur, P.; Nagaraja, G. M.; Zheng, H.; Gizachew, D.; Galukande, M.; Krishnan, S.; Asea, A. A Mouse Model for TripleNegative Breast Cancer Tumor-Initiating Cells (TNBC-TICs) Exhibits Similar Aggressive Phenotype to the Human Disease. BMC Cancer 2012, 12, 120. 
(100) Metz, R.; Rust, S.; Duhadaway, J. B.; Mautino, M. R.; Munn, D. H.; Vahanian, N. N.; Link, C. J.; Prendergast, G. C. IDO Inhibits a Tryptophan Sufficiency Signal that Stimulates mTOR: a Novel IDO Effector Pathway Targeted by D-1-Methyl-Tryptophan. Oncoimmunology 2012, 1, 1460-1468.

(101) Lu, J.; Huang, Y.; Zhao, W.; Marquez, R. T.; Meng, X.; Li, J.; Gao, X.; Venkataramanan, R.; Wang, Z.; Li, S. PEG-Derivatized Embelin as a Nanomicellar Carrier for Delivery of Paclitaxel to Breast and Prostate Cancers. Biomaterials 2013, 34, 1591-1600.

(102) Huang, Y.; Lu, J.; Gao, X.; Li, J.; Zhao, W.; Sun, M.; Stolz, D. B.; Venkataramanan, R.; Rohan, L. C.; Li, S. PEG-Derivatized Embelin as a Dual Functional Carrier for the Delivery of Paclitaxel. Bioconjugate Chem. 2012, 23, 1443-1451.

(103) Mazzucchelli, S.; Ravelli, A.; Gigli, F.; Minoli, M.; Corsi, F.; Ciuffreda, P.; Ottria, R. LC-MS/MS Method Development for Quantification of Doxorubicin and Its Metabolite 13-Hydroxy Doxorubicin in Mice Biological Matrices: Application to a Pharmaco-Delivery Study. Biomed. Chromatogr. 2017, 31, e3863.

(104) Joerger, M.; Huitema, A. D.; Meenhorst, P. L.; Schellens, J. H.; Beijnen, J. H. Pharmacokinetics of Low-Dose Doxorubicin and Metabolites in Patients with AIDS-Related Kaposi Sarcoma. Cancer Chemother. Pharmacol. 2005, 55, 488-496.

(105) Lim, Y.-W.; Goh, B.-C.; Wang, L.-Z.; Tan, S.-H.; Chuah, B.; Lim, S.-E.; Iau, P.; Buhari, S.; Chan, C.-W.; Sukri, N.; et al. Pharmacokinetics and Pharmacodynamics of Docetaxel with or Without Ketoconazole Modulation in Chemonaive Breast Cancer Patients. Ann. Oncol. 2010, 21, 2175-2182. 